\title{
Spacing and linkage of confined normal faults: Importance of mechanical thickness
}

\author{
Roger Soliva, ${ }^{1,2}$ Antonio Benedicto, ${ }^{1}$ and Laurent Maerten ${ }^{3}$ \\ Received 29 October 2004; revised 26 July 2005; accepted 4 October 2005; published 19 January 2006.
}

[1] In this paper we present the results of the analysis of fault spacing from a population of faults confined to a $4.5 \mathrm{~m}$ thick mechanical layer. We demonstrate the control of a discrete layer on the specific geometry of a so-called "domino-style" or "bookshelf" fault population. The fault population shows a logarithmic-normal frequency distribution of fault spacing, with a minimum value of spacing $S^{*}(\sim 0.25$ layer thickness $)$, revealing a nearly regular spacing distribution between the "long faults" (i.e., length greater than height), which are confined within the layer. We also observe an upper limit of fault linkage at relay ramp close to the minimum value of spacing $S^{*}$, after which free overlapping between faults having the same dip direction is allowed. On the basis of field observations, we simulate the quasi-static displacement-related Coulomb shear stress perturbation of faults of various aspect ratios (length/height). The models show that on faults that increase in aspect ratio with a constant height (as expected for the confined faults), the horizontal extent of the local stress reduction tends to localize at a constant distance from the fault surface close to $S^{*}$. For the studied case, the correspondence between the models and the field data suggests that the limited extent of the stress reduction around the confined faults controls fault spacing and fault ability to link at relay ramps. Both field data collection from different scales and modeling suggest that fault spacing in confined fault populations is linearly related to the mechanical layer thickness. We therefore highlight the importance of the thickness of layers confining faults in the evaluation of interaction, linkage and propagation of active fault segments over a broad range of scales.

Citation: Soliva, R., A. Benedicto, and L. Maerten (2006), Spacing and linkage of confined normal faults: Importance of mechanical thickness, J. Geophys. Res., 111, B01402, doi:10.1029/2004JB003507.

\section{Introduction}

[2] Fault spacing, defined as the horizontal distance measured normal to parallel faults, has been related to the stress reduction (or shadowing) around faults [Ackermann and Schlische, 1997; Cowie and Roberts, 2001]. Fault initiation and activity are inhibited and collateral propagation is retarded within the volume of stress reduction around a fault [Aydin and Schultz, 1990; Cowie et al., 1995; Cladouhos and Marret, 1996; Cowie, 1998a; Schultz, 2000; Gupta and Scholz, 2000]. The distance separating two normal faults is therefore a critical parameter for the evaluation of fault interaction through their stress field and fault activity [e.g., Aydin and Nur, 1982; Gupta and Scholz, 2000; Cowie and Roberts, 2001]. Many works have also shown that quasi-static stress interaction can lead to fault linkage, suggesting that fault coalescence depends on the

\footnotetext{
${ }^{1}$ Dynamics of Fault Systems Group, UMR-7072 Tectonique, Université Paris Sud XI, Orsay, France.

${ }^{2}$ Now at Laboratoire Dynamique de la Lithosphère, UMR-5573, Montpellier, France.

${ }^{3}$ IGEOSS, Montpellier, France.
}

Copyright 2006 by the American Geophysical Union. 0148-0227/06/2004JB003507\$09.00 extent of the shear stress perturbation around the fault [e.g., Bürgmann et al., 1994; Crider and Pollard, 1998; Schultz, 2000].

[3] Modeled geometry of the stress perturbation around theoretical faults, which are commonly related to the material properties and the stress applied [e.g., Bürgmann et al., 1994], are strongly dependent on the 3-D shape of the fault. Especially, fault aspect ratio (length/down dip height, $L / H$, commonly corresponding to the ratio of the larger to the shorter normal fault axis [Nicol et al., 1996]) and displacement are influential in terms of distribution and magnitude of the stress reduction around faults [Willemse, 1997; Crider and Pollard, 1998; Gupta and Scholtz, 2000]. Willemse [1997] shows how the zone of high shear stress reduction is more restricted as the down dip fault height decreases. These numerical modeling results suggest that longer faults (i.e., higher aspect ratio faults) should have lower spacing compare to their length than do lower aspect ratio faults.

[4] Recent studies illustrate that aspect ratios of faults from a single fault population can be strongly controlled by the thickness of the mechanical layer in which they are confined [Ackermann et al., 2001; Soliva and Benedicto, 2005]. Discontinuities between layers of contrasting lithologies, as well as thin beds or weak interfaces [Petit et al., 


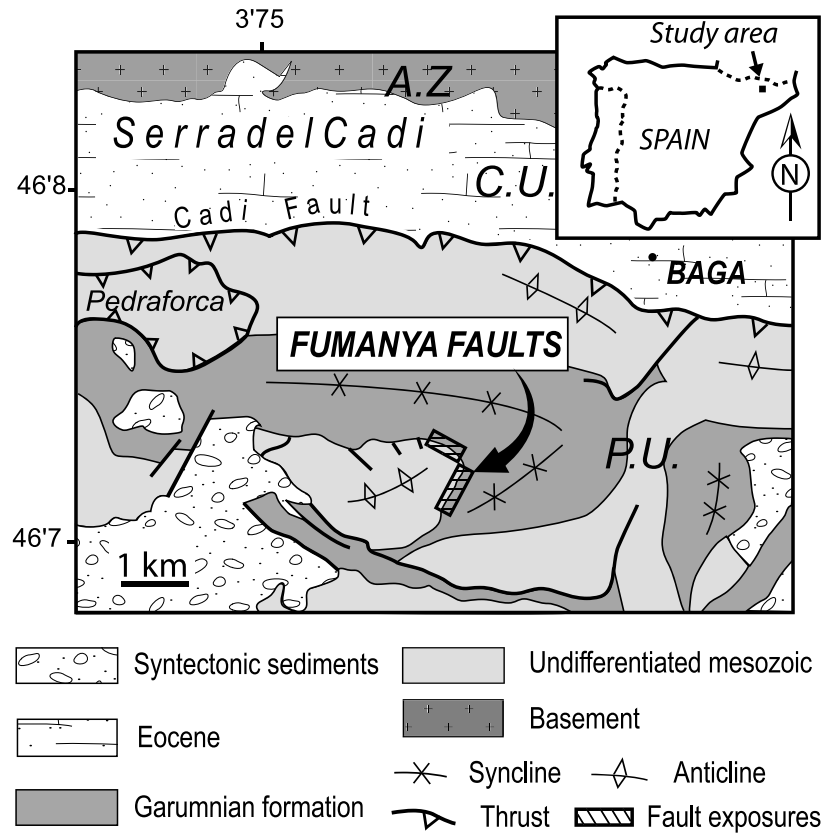

Figure 1. Location of the Fumanyá faults (Figols Quarry, Berguedá, Catalonia) in the Pedraforca thrust sheet unit. The faults are exposed on a Maestrichtian bedding plane of the early Garumnian Formation. A.Z., axial zone; C.U., Cadi unit; P.U., Pedraforca unit.

1994; Cooke and Underwood, 2001], can represent barriers to fault propagation producing vertically restricted normal fault surfaces, i.e., faults limited in height [Nicol et al., 1996; Gross et al., 1997; Wilkins and Gross, 2002]. This can lead to faults with long shapes $(L / H \gg 1$ [e.g., Nicol et al., 1996; Koledoye et al., 2000]), such as those confined to a single mechanical layer [e.g., Ackermann et al., 2001; Schultz and Fossen, 2002], and with aspect ratio up to 10 [e.g., Cartwright et al., 1995; dePolo, 1998; Schultz and Fossen, 2002; Soliva and Benedicto, 2005]. Two-dimensional modeling of a growing unconfined fault population (i.e., not vertically restricted fault [e.g., Martel and Boger, 1998]) does not exhibit a characteristic fault spacing but a random distribution that seems to be controlled by the complex stress shadowing development [Cowie et al., 1995; Cowie, 1998a]. Clay models analyses show that for a fault population confined within a mechanical layer, faults become regularly spaced when the population reaches a high-density degree (i.e., fault spacing stops evolving) [Vendeville et al., 1987; Ackermann et al., 2001; Bahroudi et al., 2003]. Similar behavior called "saturation" is commonly described in joint sets [e.g., Rives et al., 1992; Wu and Pollard, 1995]. To explain the negative exponential fault size distribution observed in their models, Ackermann et al. [2001] suggest that the dimension of the stress reduction around faults is limited when the faults grow only in length (i.e., vertically restricted). Since fault initiation and propagation are impeded within zones of stress reduction [e.g., Ackermann and Schlische, 1997; Gupta and Scholz, 2000; d'Alessio and Martel, 2004], we suggest that a nearly regular and small fault spacing compared to fault lengths should be observed between faults confined within a discrete me- chanical layer. This hypothesis, although demonstrated in joint sets [e.g., Bai and Pollard, 2000], has never been tested for a confined fault system using field observations, statistics and theory.

[5] In this paper, we analyze a field example of normal faults confined to a sedimentary sequence in which fault spacing between faults of the same dip direction is nearly regular (domino style or bookshelf faults). We focus our study together on fault displacement and ability of overlapping parallel fault segments to link, which are the main geometrical characteristics of the fault population that can explain the observed distribution of fault spacing. This analysis suggests that the geometry of fault spacing could be related to the occurrence of specific stress distributions around the studied long faults (i.e., $L / H>2$ ). Threedimensional numerical modeling is designed to analyze the specific quasi-static shear stress distribution around faults of various aspect ratios. This approach aims to show the importance of faults growing only by length (as faults grow within a discrete mechanical layer) to the shape and the extent of the zones of stress reduction surrounding the faults. Then, we discuss the consistency between field data and numerical modeling with respect to the scaling of the stress shadowing around vertically restricted normal faults. We highlight the strong importance of the mechanical thickness confining the faults on the fault population geometry, and discuss the effects of variations in material properties and fault shape over a broad range of scales.

\section{Field Data Analysis}

\subsection{Geological Setting}

[6] This study is based on a field example of a population of normal faults confined to a discrete sedimentary sequence (i.e., long faults with height limited by the mechanical stratification [also see Schultz and Fossen, 2002]) located in a quarry of lignite at the Collado de Fumanyá (Carbones de Berga S.A., Catalonia, Spain) (Figure 1). On the studied exposure, more than 500 faults are observed with an average dip angle of $60^{\circ}$ with respect to a bedding plane of a $30^{\circ}$ to $70^{\circ}$ dipping Maestrichtian continental marly limestones sequence (Figure 2). The faults show nearly parallel scarps of normal offset with respect to a same bedding plane located near the top of the marly limestones sequence. The exposure of the same bedding plane is due to a quarry rehabilitation work, which aimed at exposing well preserved sauropod tracks.

[7] The faults are observed within the Serra d'Ensije anticline of kilometric scale curvature radius. They are mainly observed in strike slip position and also as normal faults in the southern horizontal flank of the anticline. This anticline results from the interference between an E-W striking frontal thrust and a NNE-SSW striking lateral ramp [Vergés and Martines-Rius, 1988]. The thrusting began in the Maastrichtian, and from the early Eocene to the Oligocene, the deformation was expressed by out of sequence thrusts reactivating the preexisting structures [Vergés and Muñoz, 1990]. The faults were tilted and formed before the folding of the Maastrichtian sequence. The fact that there is not any regional tectonic regime of extension identified since the Maastrichtian suggests that a 

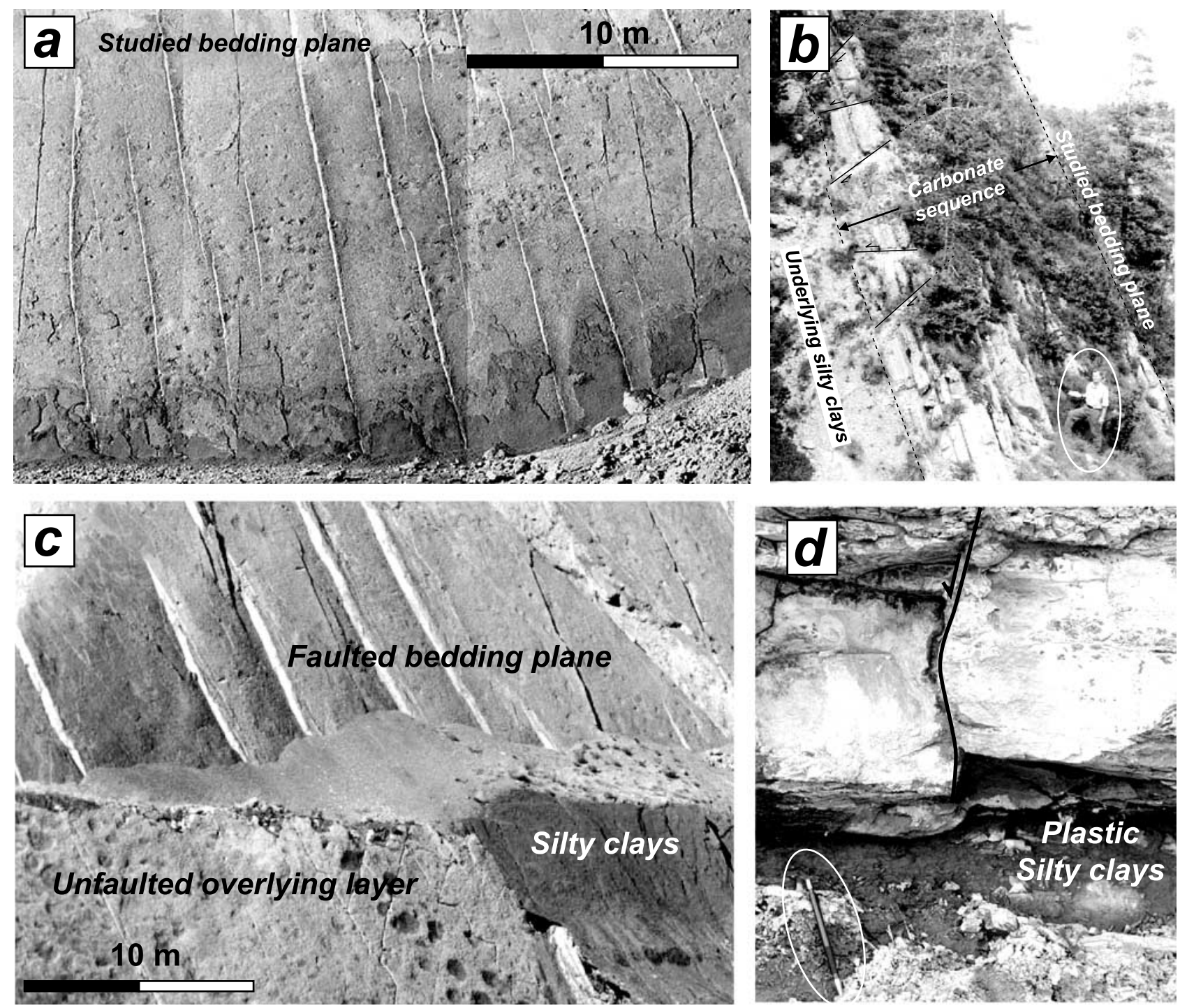

Figure 2. The studied faults. (a) An example of the faults studied at Fumanyá showing white fault scarps displacing the same bedding plane with normal offset. (b) Cross-sectional exposure of the studied faults. (c) Bedding planes exposure of the top of the studied marly limestone series showing that the faults terminate in the overlying silty clay layer. (d) Photograph of a detailed exposure of a fault termination in the underlying silty clays of plastic behavior.

local extension would have been related to the Pyrenean uplift. It is probable that the extension would have been driven by a slope of the sequence toward the south, which is both the direction of the Pedraforca unit emplacement and the major dip direction of the faults (see the large amount of south facing faults on Figure 2a) [e.g., Mandl, 1987; Vendeville et al., 1987].

[8] The studied faults are contained within the $4.5 \mathrm{~m}$ thick brittle limestone-shale carbonate sequence. They are confined (or "vertically restricted" in the terms of Gross et al. [1997]): they terminate (no discontinuous displacement at fault tip) near the boundary of the carbonate sequence within the overlying and underlying silty-clay layers (Figures $2 b$ and $2 c$ ). The detail of the lower tip of a vertically restricted fault is presented on Figure 2d, suggesting that displacement is accommodated by plastic flow in the silty-clay layer. The carbonate sequence, confining the faults, is therefore defined as a mechanical layer of $4.5 \mathrm{~m}$ thickness. The longest faults $(L \sim 40 \mathrm{~m})$ therefore have an aspect ratio of $\sim 8$ (with $H=4.5 / \sin 60^{\circ} \sim 5 \mathrm{~m}$ ) and a maximum displacement $\left(D_{\max }\right)$ of $\sim 50 \mathrm{~cm}$. $D_{\max }-L$ data of this fault population suggest that fault aspect ratios before the faults reached the bounding silty-clay levels were close to 2 [Soliva and Benedicto, 2005], which is a reasonable value for faults in sedimentary rocks [Walsh and Watterson, 1989; Nicol et al., 1996; Dawers et al., 1993].

\subsection{Fault Displacement}

[9] Fault displacement is analyzed because of its specific displacement distribution when the faults are vertically restricted [Dawers et al., 1993; Soliva and Benedicto, 2005] and because displacement distribution is described 

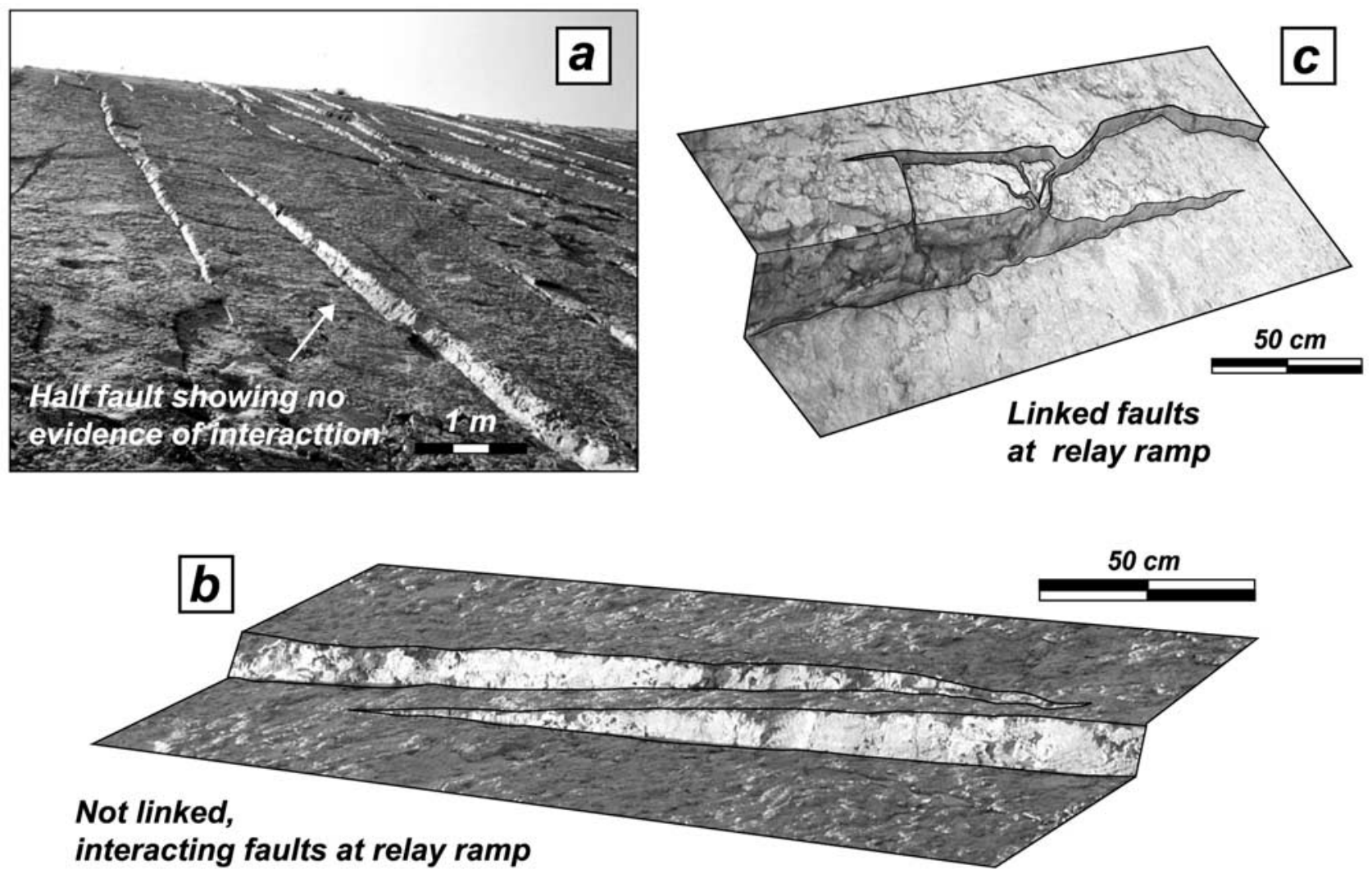

Figure 3. Examples of isolated, interacting, and linked long fault segments. (a) Photograph of two overstepping isolated half faults. The absence of high displacement gradient revealed by the fault scarps at the overstep shows that these faults did not strongly interact through their stress field. (b) Not linked interacting segments at relay ramp marked by high displacement gradients at fault ends. (c) Linked fault segments at relay ramp.

as a controlling factor of the shear stress perturbation around a fault [Willemse, 1997; Ackermann and Schlische, 1997; Cowie and Roberts, 2001]. Displacement (net slip), assessed by offset bedding plane, was measured on meterscale faults utilizing millimeter- to meter-scale rulers. Displacement profiles were measured as scarp height versus distance along the scarps with respect to the fault plane striation. On long faults $(L>8 \mathrm{~m}$, and then $L / H>2)$ displacement profiles were established from photographs of fault scarps revealing clean fresh fault surfaces (Figures 2 and 3). Photographs were captured with digital-video camera with the optic axis oriented normal to the fault plane. Using laser theodolite and tape measurements, we calibrated the dimensions of the fault scarps and constructed displacement profiles. The major source of error is the fault scarp erosion, estimated at about $\pm 1 \mathrm{~cm}$ on the measured faults.

[10] We focus here on the analysis of the displacement of isolated half faults (Figure 3a), on which a particular attention has been given in their identification. Isolated half faults are defined as fault parts comprised between $D_{\max }$ and one of the fault tip, showing no evidence of mechanical interaction with other surrounding faults [Willemse et al., 1996; Gupta and Scholz, 2000; Soliva and Benedicto, 2004], i.e., without relay ramps or breaching allowing transfer of displacement to a another fault (Figures $3 \mathrm{~b}$ and $3 c$ ). A relay ramp (see Figures $3 b$ and $3 c$ ) is defined as a volume of rotation between two normal fault segments that overstep along strike and that have the same dip direction [Larsen, 1988].

[11] The $D_{\max }-L$ data of the population are presented in Figure 4 (see Soliva and Benedicto, [2005] for a comparison with the average displacement). Note that the number of isolated half faults measured does not represent the real proportion of faults per length range (see section 2.3), because on large faults (1) segmentation and linkage are frequent, (2) $D_{\max }$ can be out of the plane of exposure, and (3) scarp degradation is sometimes large. A break in the $D_{\max }-L$ scaling is clearly observed since the faults approaches the half length of $\sim 4 \mathrm{~m}$ (Figures $4 \mathrm{a}$ and $4 \mathrm{~b}$ ). The first set, composed of short faults (grey dots), is best fit by a power law with exponent $n$ close to $1\left(D_{\max }=\gamma L^{n}\right.$, with $n=0.99, \gamma=0.033$ and determination coefficient $R^{2}=$ 0.91 ), therefore nearly linear. In contrast, larger faults of $H \sim$ $5 \mathrm{~m}$ (black dots) show a highly nonlinear trend, with the exponent $n=0.21\left(\gamma=0.13\right.$ and $\left.R^{2}=0.72\right)$, revealing a very low increase in displacement with fault lengthening. This behavior is also observed on vertically restricted faults at the base of a $\sim 2 \mathrm{~m}$ thick layer (white dots, for which fault spacing cannot be considered because of the small size of the outcrop) showing displacement dependence on fault depth. The displacement saturation on the studied faults is expressed on a displacement profile by a reduction in the horizontal displacement gradient and a change in the shape 


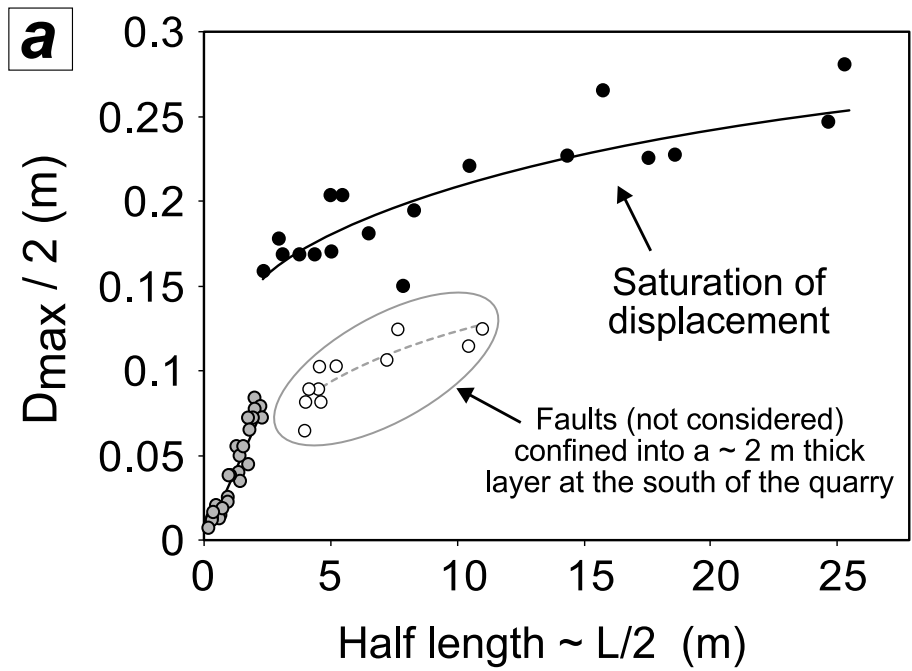

Short faults
$D_{\max }=0.033 L^{0.99} ; R^{2}=0.91$

- Long faults of $\mathrm{H} \sim 5 \mathrm{~m}$

$D_{\max }=0.13 L^{0.21} ; R^{2}=0.72$

\section{( $\circ$ Long faults of $\mathrm{H} \sim 2.3 \mathrm{~m}$ ) \\ $D_{\max }=0.045 \mathrm{~L}^{0.44} ; \mathrm{R}^{2}=0.68$}

\section{Best fit for all Faults \\ $D_{\max }=0.033 L^{0.76} ; R^{2}=0.88$}

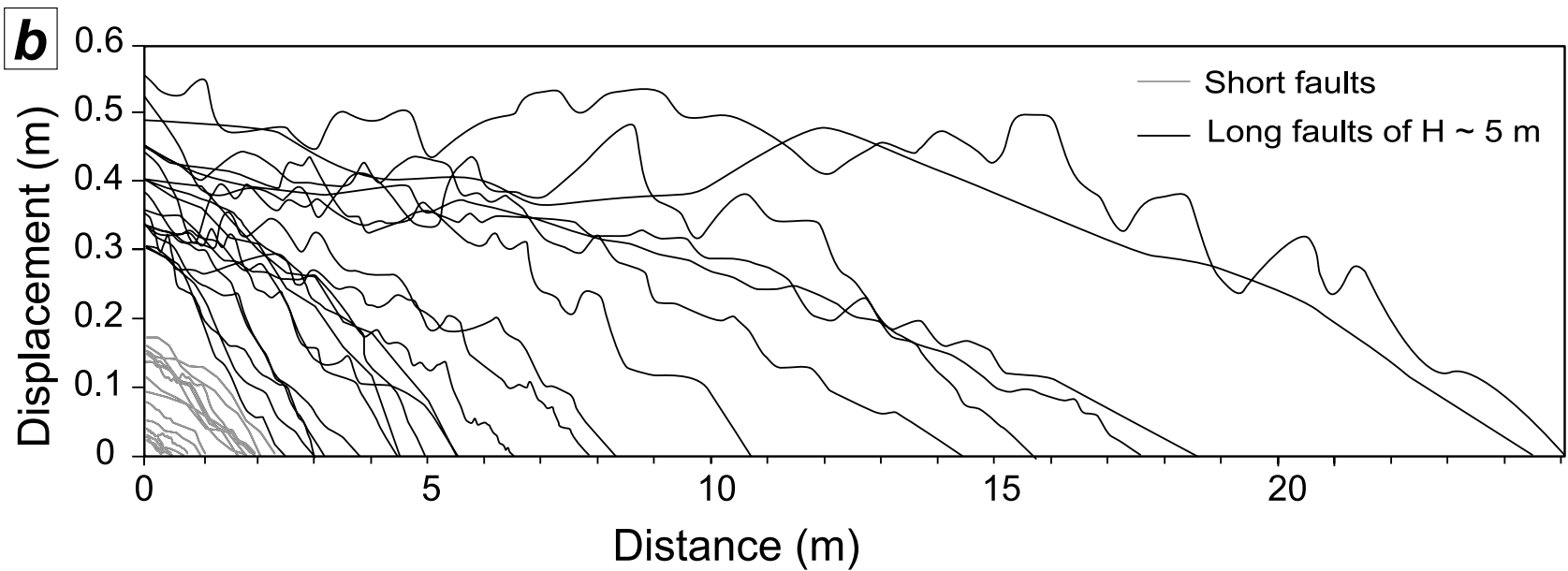

Figure 4. (a) $D_{\max }-L$ graph of the studied normal faults (grey and black dots) and also for faults confined into a layer of smaller thickness from the south of the quarry (white dots). The half length is the distance between $D_{\max }$ and fault tip, i.e., $\sim L / 2$. (b) Displacement profiles of the studied faults, i.e., grey and black dots in Figure 4a.

of profile as a function of fault length (Figure 4b). Normalization of the displacement profiles of the isolated faults exhibits the clear difference in profile shape. The faults have been sorted into short faults (half length $<4 \mathrm{~m}$, Figure 5a) and long faults (half length $>4 \mathrm{~m}$, Figure $5 \mathrm{~b}$ ). The profiles of short faults, explained by a single linear fit between $D_{\max }$ and the fault tip (see the equation in Figure 5a), are generally peak shaped. This is a common characteristic of isolated faults that are not pinned or do not cut rocks of different rheology [Muraoka and Kamata, 1983; Peacock and Sanderson, 1991; Bürgmann et al., 1994; Nicol et al., 1996, Cowie and Shipton, 1998; Manighetti et al., 2001]. The profiles of long faults can be divided into two near linear parts of different slope (see equations in Figure 5b) separated by a smooth deflection point. These faults exhibit flat-topped profiles, especially in the longest faults (Figure 4b). The slope of the part between $D_{\max }$ and the deflection point can be less than 0.01, and the part between the deflection point and the fault tip equals or is much lower than the gradient on small faults $(\sim 0.075)$ (Figure 4b, and see Soliva and Benedicto [2005] for best fit trends on individual profiles). This demonstrates that the flat topped shape is not due to fault interaction (also see Dawers et al. [1993] for faults and Petit et al. [1994] for mode I fractures), which commonly leads to a strong increase of displacement gradient at fault end over the value of isolated faults [e.g., Peacock and Sanderson, 1991; Willemse et al., 1996; Gupta and Scholz, 2000]. In particular, Soliva and Benedicto [2004] show that the increase of displacement gradient at interacting fault tips can be up to $\sim 2.5$ times the average tip gradient of isolated faults in this fault system (Figure 3b).

[12] Flat-topped fault displacement distribution along strike is well documented from field data [Dawers et al., 1993; Fossen and Hesthammer, 1997; Manighetti et al., 2001] and is consistent with stratigraphic restriction when it appears as a function of fault length, and when the $D_{\max }-L$ scaling is best fitted by a power function with exponent $n<1$ [Schultz and Fossen, 2002; Soliva and Benedicto, 2005]. Since fault displacement is a function of the fault dimensions [e.g., Cowie and Scholz, 1992; Willemse, 1997], a constant fault height, which is controlled by the thickness of the layer confining the faults, must therefore control the observed displacement [Schultz and Fossen, 


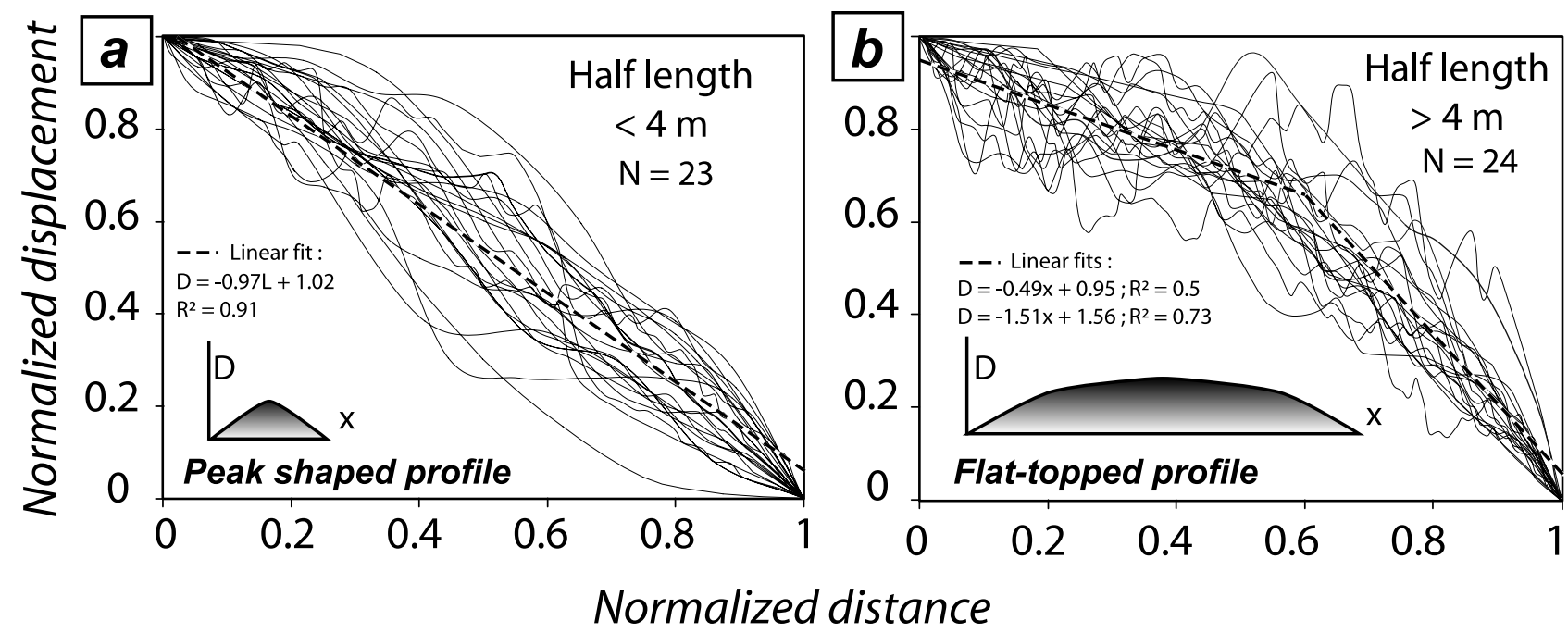

Figure 5. Normalized displacement profiles between $D_{\max }$ and fault tip of (a) short and (b) long isolated half faults from Figure 4a. Dashed lines are linear fits with equations labeled.

2002]. On the flat topped profiles of the long faults (Figure $5 \mathrm{~b}$ ), the zones having low gradients between $D_{\max }$ and the deflection point reflect the restricted central part of the fault surface, which must have a nearly constant height, whereas the zones of steeper displacement gradient between the deflection point and the fault tip represent the parts of the fault that are not vertically restricted [Soliva and Benedicto, 2005]. The following of the paper focuses on the spatial distribution of these long faults equipped with flat-topped displacement distribution.

\subsection{Fault Spacing}

[13] With respect to fault exposure, we analyze fault spacing because of the regular distribution observed for the long confined faults (Figures $2 \mathrm{a}$ and $2 \mathrm{c}$ ). The aim of this section is therefore to quantify the fault spacing between these long faults using the field data.

[14] The statistics of spacing of the fault population have been analyzed from a detailed mosaic of photographs of the bedding, captured with a high-resolution digital camera (a pixel surface on the mosaic corresponds to $1.4 \times 10^{-4} \mathrm{~m}^{2}$ in field). The fault population data were measured using pixel counter software on a well-resolved photo interpretation, with the scale calibrated using laser theodolite measurements (Figure 6a). Fault spacing was recorded along six $200 \mathrm{~m}$ long scan lines perpendicular to the average fault strike, as measured in fracture sets [e.g., Narr and Suppe, 1991; Rives et al., 1992; Gross, 1993]. This method of measurement is correct since the fault size distribution of the population studied is not fractal (Figure 7). On cumulative frequency graphs, the increase of the negative slope with respect to fault length (negative exponential trend [e.g., Spyropoulos et al., 1999]) reveals a larger proportion of large faults compared to a linear power law distribution (also see the same discussion by Soliva and Benedicto [2005] for the same fault system, Ackermann et al. [2001] in monolayer clay models and Cowie [1998b] for faults at mid-ocean ridges). This nonfractal distribution therefore justifies the use of scan lines, which allows us to avoid the measuring of fault spacing between short faults, or between long and short faults. Scan lines therefore mainly detect the spacing between (long) vertically restricted faults (see Figure 6a), which is the aim of our analysis.

[15] Figure 6b shows the frequency distribution of fault spacing for three different fault configurations: horst, graben and the same dip direction. This graph reveals that all fault configurations show logarithmic-normal tendency, with correlation coefficients of $R^{2} \sim 0.97$. It is important to note that this logarithmic-normal tendency is not related to a truncation bias, which begins on scan lines under $\sim 5$ times the side size of a pixel, i.e., under $\sim 6 \mathrm{~cm}$ along the scan lines in the field. The fault configuration of the same dip direction is the most frequent case, representing $60.1 \%$ of the three fault configurations. Faults with the same dip direction also show logarithmic-normal tendency with correlation coefficients of $R^{2} \sim 0.97$, revealing its strong influence on the distribution of all fault configurations. Graben and horst configurations show more normal distributions with a mode (maximum frequency) located $\sim 3-$ $4 \mathrm{~m}$ spacing, but have little influence on the entire population statistics because of their low proportions. The mode of the graben configuration (spacing $\sim 3 \mathrm{~m}$ ) indicates two possible geometries at depth: (1) an X-fault geometry (conjugates with $60^{\circ} \mathrm{dip}$ ) within the $4.5 \mathrm{~m}$ thick carbonate sequence, in which the faults intersect at the center of the layer or (2) a V-fault geometry within the half sequence (i.e., within an upper layer $2.25 \mathrm{~m}$ thick), in which the faults intersect at the base. The spacing between conjugate normal faults probably depends on the observed $\mathrm{X}$ or $\mathrm{V}$ configurations [e.g., Golombec, 1979] that satisfy the symmetry condition of the initiation of conjugate normal faults [Scholz and Contreras, 1998] and could also be related to the properties of the mechanical discontinuities [Bahroudi et al., 2003]. This suggests that spacing between faults of opposite and same dip direction results from different processes. The fact that the fault configuration of the same dip direction is the most frequent case (see above) justifies the particular attention given in this paper to the spacing between fault surfaces that are parallel to one another. 

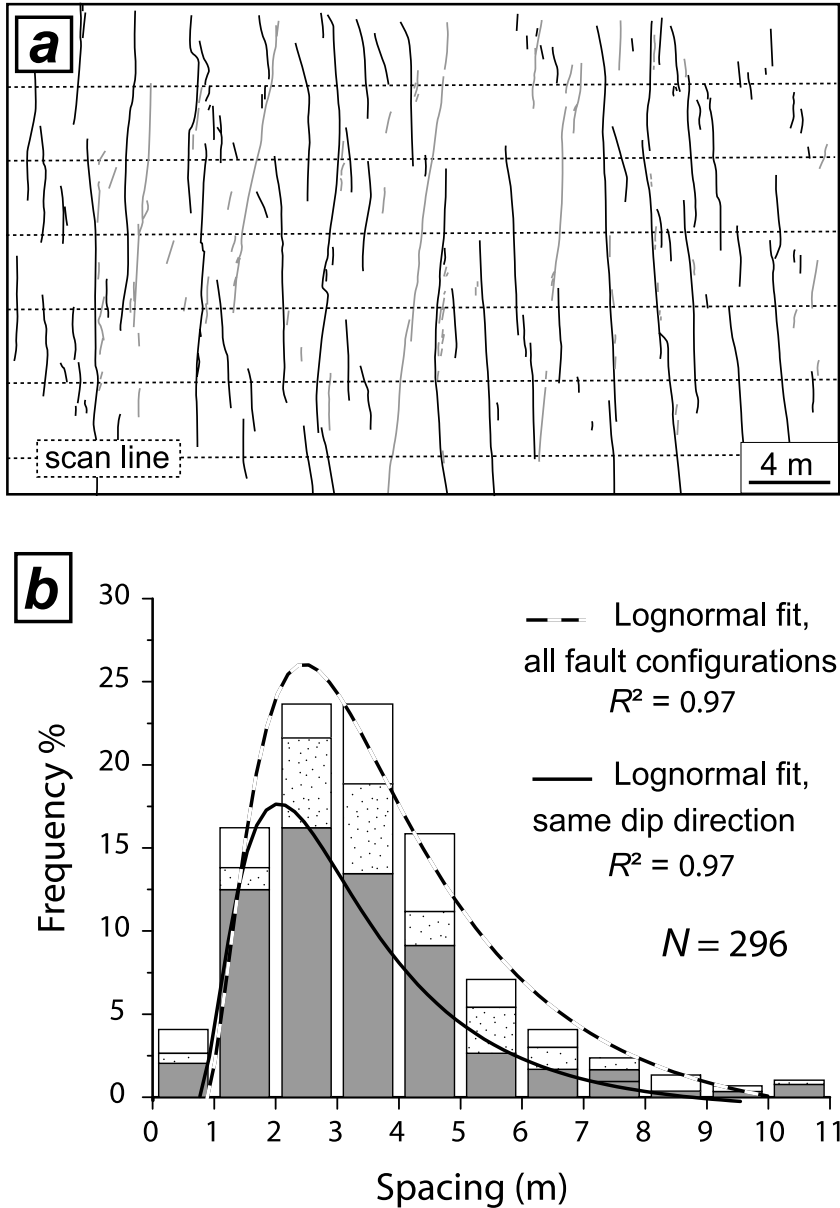

Fault configurations :

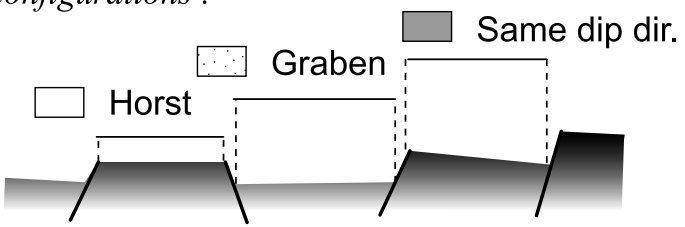

Figure 6. Spacing of the fault population. (a) Window of the scale calibrated photo mosaic interpretation of the bedding plane containing the studied fault population. Dark and grey lines are the conjugate south and north facing fault scarps, respectively. Broken lines are scan lines equally spaced by a distance of $5 \mathrm{~m}$. (b) Histogram showing the frequency of fault spacing along six scan lines $\sim 200 \mathrm{~m}$ long. $N$ is the number of detected intersections between the faults and the scan lines. Spacing between faults having the same dip direction, in horst and graben configurations, is distinguished. Dashed and solid lines are logarithmicnormal fits for all configurations and for faults of the same dip direction, respectively. Least squares determination coefficients $\left(R^{2}\right)$ are labeled.

[16] The logarithmic-normal tendency of faults having the same dip direction reveals an asymmetric distribution with a strong increase of spacing between 0 and $2 \mathrm{~m}$, a well defined mode between 2 and $3 \mathrm{~m}$, and a gentle decrease after $3 \mathrm{~m}$. The zone on the graph of steep frequency gradient corresponds to a spacing of $1 \mathrm{~m}$. This defines a lower bound of spacing $(\sim 1 \mathrm{~m})$ and a nearly regular distribution between the faults detected. Small spacing $(S<1 \mathrm{~m})$ is represented in the field by (1) very short faults that intersect the scan line close to a long fault, (2) when the scan line intersects two closely spaced short faults, or (3) when the scan line crosscut a relay ramp between two faults (see Figure 6a). This minimum spacing, as well as the nearly regular spacing revealed by the logarithmic-normal distribution, therefore applies to long faults away from relay ramps.

[17] This regular spacing is a strong characteristic of the fault population (also see the fault spacing in the clay models of Ackermann et al. [2001]). A possible reason for the occurrence of the minimum spacing observed between long faults will be discussed in the following section with respect to the process of fault linkage.

\subsection{Fault Linkage and the Minimum Value of Spacing}

[18] Two kinds of fault segmentation are observed on the studied exposure. First, fault segmentation is observed near the end of long faults. This kind of segmentation is interpreted as the result of the propagation of single fault that breaks down into different segments [Walsh et al., 2003; Marchal et al., 2003]. Second, segmentation results from the propagation and linkage of initially isolated faults [e.g., Peacock and Sanderson, 1991]. This second scenario could explain the frequent observations of "incoherent" displacement profiles (different displacement profiles than those of isolated faults [e.g., Childs et al., 1995]) along the segmented faults observed by Soliva and Benedicto [2004] in the same fault system. Since fault population generally grow by segment linkage [e.g., Cartwright et al., 1996], this

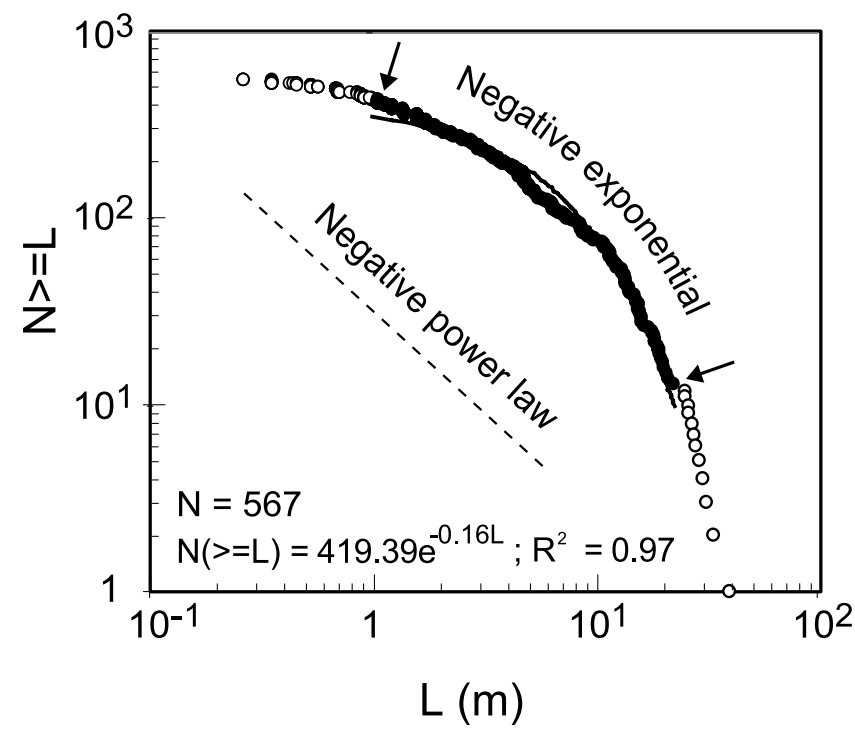

Figure 7. Logarithmic graph of cumulative fault length $(L)$ frequency. $N$ is the number of faults. The black line is the best fit exponential. Equation and least squares coefficient $\left(R^{2}\right)$ are labeled. Good exposure of the faults and high-resolution imaging of the scale calibrated photo mosaic lead to a truncation bias (lower bias due to the photo mosaic resolution) for $L<1 \mathrm{~m}$. Best fit has been calculated with only faults of $1<L<25 \mathrm{~m}$ (black dots) in order to avoid truncation and censoring bias (upper bias due to the size of the outcrop). 


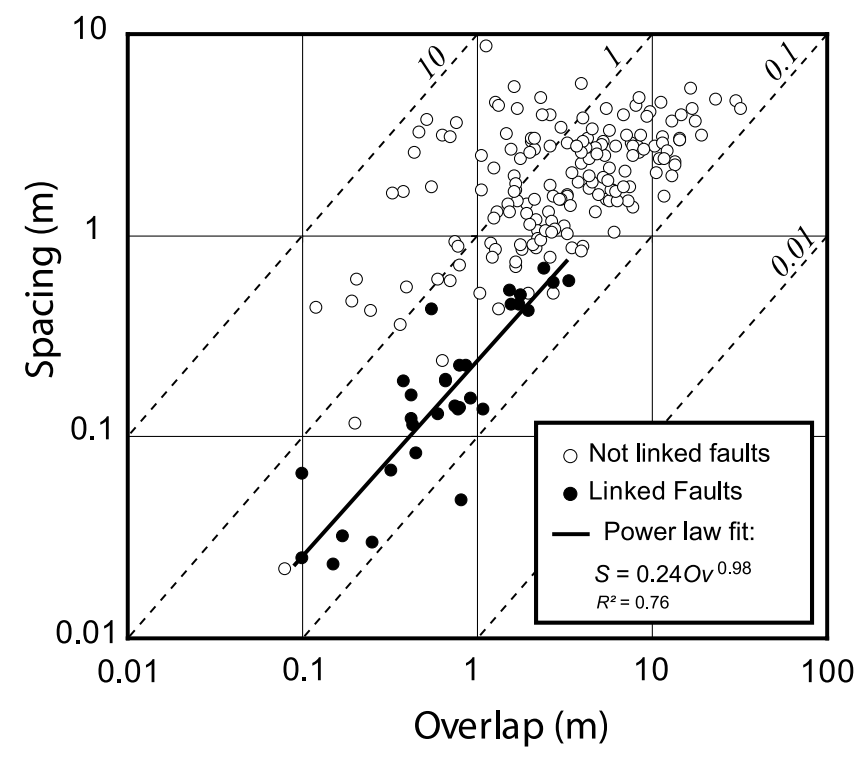

Figure 8. Bilogarithmic graph of overlap (Ov) versus spacing $(S)$ of overlapping faults of the same dip direction observed on the same bedding plane. Nonlinked and linked normal faults are distinguished by different symbols. Dashed lines show constant $\mathrm{Ov} / \mathrm{S}$ ratio, with values labeled. The solid line is the best fit law for linked faults. Equations and least squares determination coefficient $\left(R^{2}\right)$ are labeled.

second kind of fault segmentation seems of major importance in controlling the fault spacing distribution.

[19] We have measured the values of overlap (Ov, distance parallel to the fault along which two faults can overlap) and spacing $(S)$, between faults of the same dip direction, on the same photograph mosaic on which fault spacings have been measured. Figure 8 is a graph of Ov versus $S$, represented by different symbols for overlapping nonlinked faults (see for example Figures $3 \mathrm{a}$ and $3 \mathrm{~b}$ ) and faults that are linked at relay ramps (two segments linked by one or more throughgoing faults, Figure 3c [e.g., Peacock and Sanderson, 1991; Trudgill and Cartwright, 1994]). Nonlinked faults are marked by a scattered wide range of overlap and spacing frequently over $1 \mathrm{~m}$. In contrast, linked faults can be explained by a power law fit $\left(\mathrm{Ov}=\alpha S^{n}\right)$ with $\alpha=0.24$ and $n=0.98$, therefore nearly linear. This relationship has an upper scalar bound, near $S=1 \mathrm{~m}$, after which the faults are not linked and do not show relay ramps.

[20] The upper scalar bound of this relation reveals that fault interact and reach linkage if they step by less than $1 \mathrm{~m}$. If the faults step by more than $1 \mathrm{~m}$, the faults do not link and propagate past each other (Figure $2 \mathrm{a}$ ). This critical value of spacing is consistent with the characteristic minimum spacing observed between long faults (Figure 6b), suggesting that the upper scalar bound of the linkage process between the vertically restricted faults accounts for the final minimum value of spacing observed in Figure 6 . We suggest that the dimension of the stress shadowing around the vertically restricted faults should not increase proportionally with the increase of fault length because (1) fault linkage at relay ramps seems mainly related to the distribution of stress between overlapping faults segments [Crider and Pollard, 1998; Kattenhorn et al., 2000], (2) the stress perturbation is related to fault dimensions and displacement distribution [e.g., Willemse, 1997; Gupta and Scholz, 2000], and (3) the faults are not self similar in shape and displacement since they are restricted (Figures 4 and 5). In the next section we use numerical modeling to estimate how the perturbed shear stress field should evolve around faults growing only by lengthening.

\section{Insight From 3-D Numerical Modeling}

[21] In this section we model the shear stress distribution around active faults using Poly3D, a three-dimensional boundary element computer program based on linear elasticity theory [Jaeger and Cook, 1979] and a discontinuity surface composed of polygonal elements [Thomas, 1993]. This numerical code has been used to model 3-D quasistatic stress distributions around simple or complex fault geometries and the mechanical interaction between faults [Willemse, 1997; Crider and Pollard, 1998; Maerten et al., 1999; Kattenhorn et al., 2000]. We must keep in mind that Poly3D models displacements and stresses of a single slip event. The incremental perturbed stress field around fault strongly depends on the displacement distribution of a rupture event [e.g., Willemse, 1997]; therefore, because the dimensions of stress drop zones are larger than those of stress increase [see Cowie and Scholz, 1992; Schultz and Fossen, 2002, and references therein], statistically, the cumulative displacement should be indicative of the cumulative perturbed stress field around faults. Then, modeling rupture events with displacement distribution consistent with the cumulative distribution observed on faults should give a reasonable approximation of the extent of the cumulative stress perturbation [see also Gupta and Scholz, 2000; Scholz and Gupta, 2000; Schultz, 2000]. Here, we normalize the values of calculated stress in order to avoid speculations about stress magnitudes.

\subsection{Modeling of the Studied Faults}

[22] Since the displacement distribution of faults governs the shear stress distribution around faults and is in turn strongly sensitive to fault shape [Willemse, 1997; Crider and Pollard, 1998; Maerten et al., 1999], we pay a particular attention to the fault shape in order to reproduce quasi-static stress perturbation. Although an elliptical tip line geometry would be a good approximation of the shape for isolated faults if the rock strength is constant around the fault tip line [Barnett et al., 1987; Nicol et al., 1996; Martel and Boger, 1998], this geometry does not generally satisfy the expected tip line geometry of vertically restricted faults (Figure 9a), which must have linear-horizontal upper and lower tips [Nicol et al., 1996; Benedicto et al., 2003]. Works from the literature based on 3-D seismic survey shows that horizontally segmented faults have linear vertical tips at the interacting fault ends [Childs et al., 1995; Huggins et al., 1995; Nicol et al., 1996]. Vertically restricted faults that are horizontally segmented should therefore have rectangular fault shapes (Figure 9a). A rectangular fault geometry also seems to be a reasonable approximation of circumstances where the layer-parallel fault dimension is significantly larger than the layer-normal dimension. Furthermore, linear vertical tip lines are also frequently observed in 3-D seismic reflection survey and analogue 


\section{a. Possible fault geometry}

\section{Non-restricted fault}

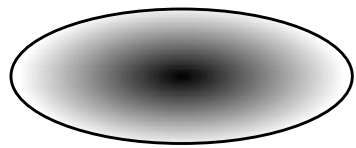

Vertically restricted fault

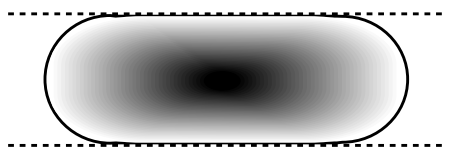

Horizontally and vertically restricted fault

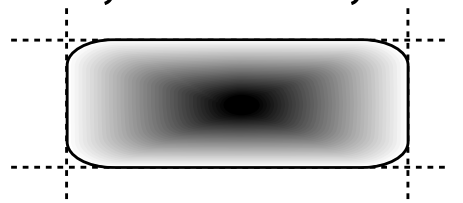

\section{b. Model setting}

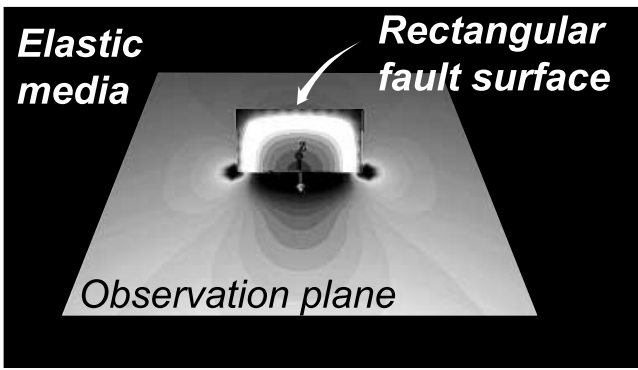

\section{c. Comparison of fault displacement with field data}

Modelled profile for a rectangular fault shape

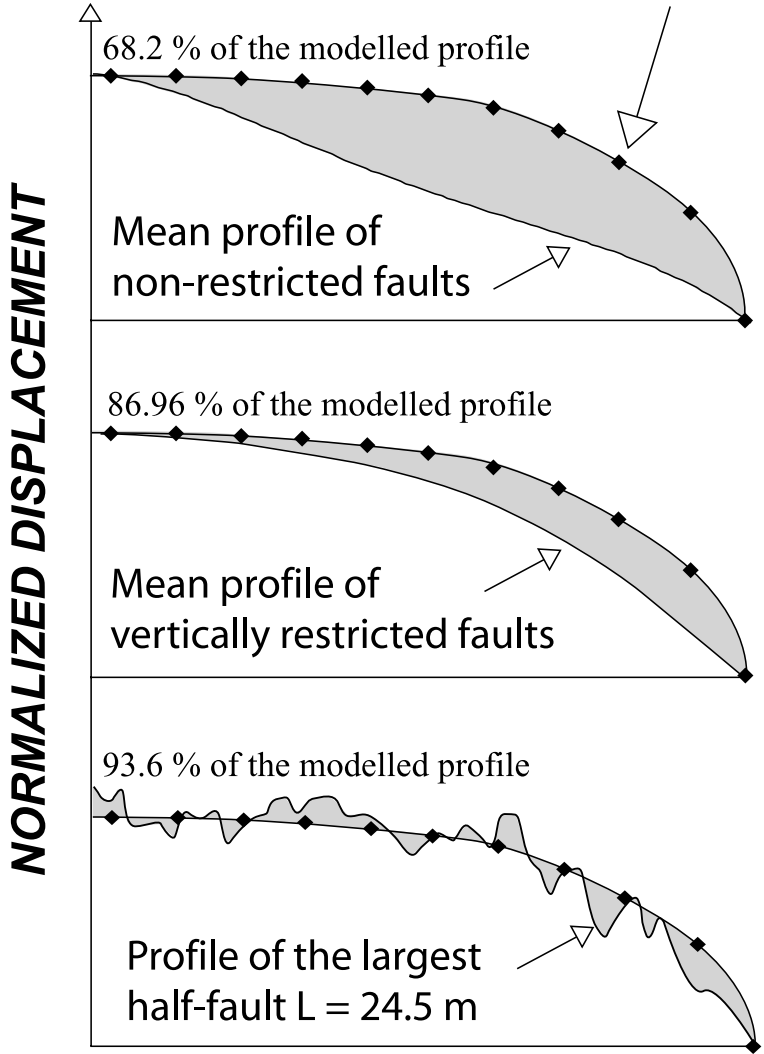

NORMALIZED LENGTH

Figure 9. Fault shapes used in the model. (a) Examples of three different fault shapes. An elliptic tip line is consistent with isolated faults growing in a homogeneous media. A horizontal tip line shape is consistent with vertically restricted faults. A square fault is consistent with vertically and horizontally restricted faults, or vertically restricted and horizontally interacting fault. See text for explanations. (b) Poly3-D model of a square fault $(L=H=5 \mathrm{~m})$ with a horizontal observation plane passing through its center. Differences of grey tones represent the slip distribution on the fault and the related shear stress distribution on the observation plane. (c) Comparison of the computed normalized displacement profile for a rectangular faults with (top) the polynomial mean profile (order 4) of isolated short half faults (see Figure 4a), (middle) the polynomial mean profile (order 4) of the long half faults (vertically restricted faults) (see Figure 4b), and (bottom) the longest vertically restricted half fault. Grey areas show the discrepancy between observed and modeled displacements. Areas underneath the profiles have been calculated and allow the quantitative comparison of the observed displacements to the modeled displacements; see proportions above each graph.

modeling on fault tips isolated from surrounding fault tips [Childs et al., 1995; Mansfield and Cartwright, 1996; Leveille et al., 1997; Guglielmo et al., 2000; Kattenhorn and Pollard, 2001; Marchal et al., 2003]. We therefore decided to idealize the vertically restricted faults of the Fumanyá fault population as $60^{\circ}$ dipping rectangular surfaces in the homogenous elastic space (Figure 9b).

[23] We test the validity of the rectangular fault assumption comparing the observed normalized displacement profiles of the studied faults (Figure 5) with those resulting from modeling a rectangular fault (Figure 9c). Although linear elasticity does not generally reproduce observed fault displacement distributions, which are generally quasi-linear (compare the polynomial profiles of short faults with the computed profile on Figure 9c), the resulting displacement distribution computed here is not so far from to the polynomial mean displacement distribution of all the long vertically restricted isolated faults $(86.96 \%)$, and fit closely to the longest fault (93.6\%) (Figure 9c, also see Cowie et al. [1994]). The computed normalized stress field calculated with Poly3D around rectangular fault shapes should therefore be a reasonable approximation of the normalized cumulative quasi-static stress field around the observed long faults on field.

[24] Because displacement profiles from long vertically restricted faults are quite well reproduced by a rectangular 


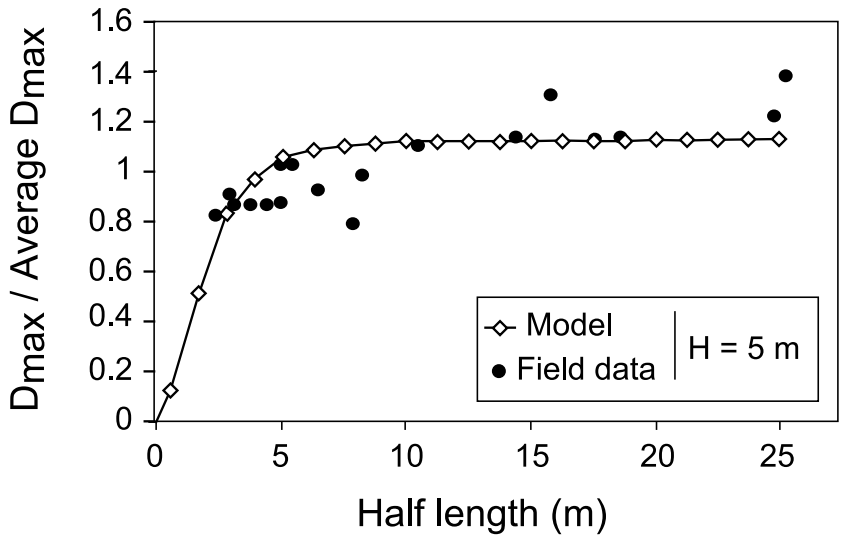

Figure 10. Comparison of normalized $D_{\max }-$ half length values from the models and field data for faults of $H=5 \mathrm{~m}$. $D_{\max }$ values are normalized by the average value of $D_{\max }$ in each data set.

fault geometry, we do not apply any shear strength profiles within the faults to reproduce fault end tapering, which only affects the stress concentration near the fault tip. This allows us to avoid any speculation about friction or cohesive end zones in the modeled faults.

\subsection{Boundary Conditions and Output}

[25] The material properties used are defined by a Poisson's ratio $v=0.25$, a shear modulus $G=1 \mathrm{GPa}$ and a density of the overburden $\rho=2000 \mathrm{~kg} \mathrm{~m}^{-3}$. These constants are consistent with common values of carbonate sedimentary rocks [Hatheway and Kiersch, 1989]. The faults are subjected to a lithostatic load, such that $\sigma_{\mathrm{V}}=\rho g z$, where $g$ is the gravitational acceleration and $z$ is the depth within the Earth. A horizontal compressive confining stress reduced by a tectonic constant, is also applied. The confining pressure is resolved following a hypothetic uniaxial strain model in which $\sigma_{\mathrm{H}}=[v /(1-v)] \sigma_{\mathrm{v}}[$ Jaeger and Cook, 1979, p113]. The horizontal constant tectonic tension $(T<0)$, is added perpendicular to fault strike, in order to simulate a less compressive stress $\left(\sigma_{\mathrm{h}}=\sigma_{\mathrm{H}}+T\right)$. These conditions lead to a stress system remotely applied such that $\sigma_{1}=\sigma_{\mathrm{V}}, \sigma_{2}=\sigma_{\mathrm{H}}$ and $\sigma_{3}=\sigma_{\mathrm{h}}$. The lithostatic load gradient is neglected because of the small fault dimension $(H \leq 5 \mathrm{~m})$, which also justifies the use of homogenous elastic space rather than elastic half-space.

[26] The maximum Coulomb shear stress $\left(S_{\mathrm{c}}\right)$ is described in linear elasticity theory as a criterion for shear failure [Jaeger and Cook, 1979, p. 95]. In our models, $S_{\mathrm{c}}$ has been calculated in the volume of rock surrounding the faults. The maximum Coulomb shear stress is defined as

$$
S_{\mathrm{c}}=\left[\frac{\left(\sigma_{1}-\sigma_{3}\right)}{2}\right] \sqrt{1+\mu^{2}}-\mu\left[\frac{\left(\sigma_{1}+\sigma_{3}\right)}{2}\right]
$$

where $\mu$ is the coefficient of internal friction $(\mu=0.6)$. We analyze the distribution of $S_{\mathrm{c}}$ on horizontal observation grids, crossing the faults through their centers (Figure 9b).

[27] The shear stress perturbation around faults has been used as a criterion for new fault initiation [Crider and Pollard, 1998; Ackermann and Schlische, 1997] and collat- eral fault propagation [Aydin and Schultz, 1990; Willemse, 1997; Gupta and Scholz, 2000]. This is based on the fact that no faults can initiate or propagate when perturbed $S_{\mathrm{c}}$ (local value of $S_{\mathrm{c}}$ in the volume near a fault) does not reach the inherent shear strength of the material [Jaeger and Cook, 1979, p. 96]. We propose that modeling of $S_{\mathrm{c}}$ is a relevant criterion to infer the spacing between faults having the same dip direction.

\subsection{Stress Reduction Extent Around Lengthening Faults}

[28] Here, we analyze the stress distribution around faults of different aspect ratios. We aim to simulate the distribution of $S_{\mathrm{c}}$ at slip events of different growth stages of a fault having a constant down dip height $\left(H_{\max }=5 \mathrm{~m}\right)$. This is consistent with the development of faults at Fumanyá, which are expected to grow only by length with a constant height $\left(H=4.5 / \sin 60^{\circ} \sim 5 \mathrm{~m}\right)$ after they reach the boundaries of the carbonate sequence. The condition of constant height implies the asymptote of $D_{\max }$ toward a constant value and therefore leads to a first-order approximation of confined faults observed in the field (Figure 10, also see Olson [2003] for the same scaling of modeled aperture of confined fractures). The amount of displacement (in theory, a function of the stress applied and the elastic constants) governs the magnitude of stress drop, but does not control the extent of the stress reduction zone [e.g., Willemse, 1997], which depends more on the displacement distribution (Figure 9c) [e.g., Gupta and Scholz, 2000] and strongly on the short fault dimension (Figure 11). Figures 11a, 11b, and 11c show the contours of perturbed $S_{\mathrm{c}} /$ remote $S_{\mathrm{c}}$ on horizontal observation planes for faults of different lengths $(L=10 \mathrm{~m}, 20 \mathrm{~m}$, and $40 \mathrm{~m})$ with constant height $(H=5 \mathrm{~m})$. On each model presented, the normalized shear stress strongly decreases near the fault plane and increases near fault tips. The length of the zone of low values of $S_{\mathrm{c}}$ (here in white, within which $S_{\mathrm{c}}<0$ ) is proportional to the fault length, but the width of this low shear stress zone remains approximately constant along the modeled faults.

[29] Figure 12a shows profiles of perturbed $S_{\mathrm{c}} /$ remote $S_{\mathrm{c}}$, along the horizontal axis from the fault center and normal to fault strike, for two faults having different aspect ratios $(L / H=2$ and $L / H=8$, see the faults of Figures 11a and 11c). The profiles are quite similar and reveal that the stress drop gradient is maximum around a value of perturbed $S_{\mathrm{c}} /$ remote $S_{\mathrm{c}}=0$. The contour position of perturbed $S_{\mathrm{c}}=0$ can therefore be used as the indicator of the extent of the stress drop near the fault. A simple way to represent the scaling of the stress shadowing with respect to fault length is to refer to the position of the contour perturbed $S_{\mathrm{c}} /$ remote $S_{\mathrm{c}}=0$ along the horizontal axis from the fault center shown in Figure 12a. A graphical representation is shown in Figure $12 \mathrm{~b}$ illustrating the position of the stress drop along the horizontal axis for faults having various aspect ratios. When the aspect ratio remains constant, the contour position of the perturbed $S_{\mathrm{c}}=0$ (i.e., the position of the stress drop) evolves linearly with fault length. In contrast, the evolution of perturbed $S_{\mathrm{c}}=0$ asymptotes toward a constant distance from the fault plane when the faults have a constant height. See especially the case where $H=5 \mathrm{~m}$ (as it is the case for the studied long faults), showing that perturbed $S_{\mathrm{c}}=0$ asymptotes toward a distance $\sim 1 \mathrm{~m}$ (see the bold line). 


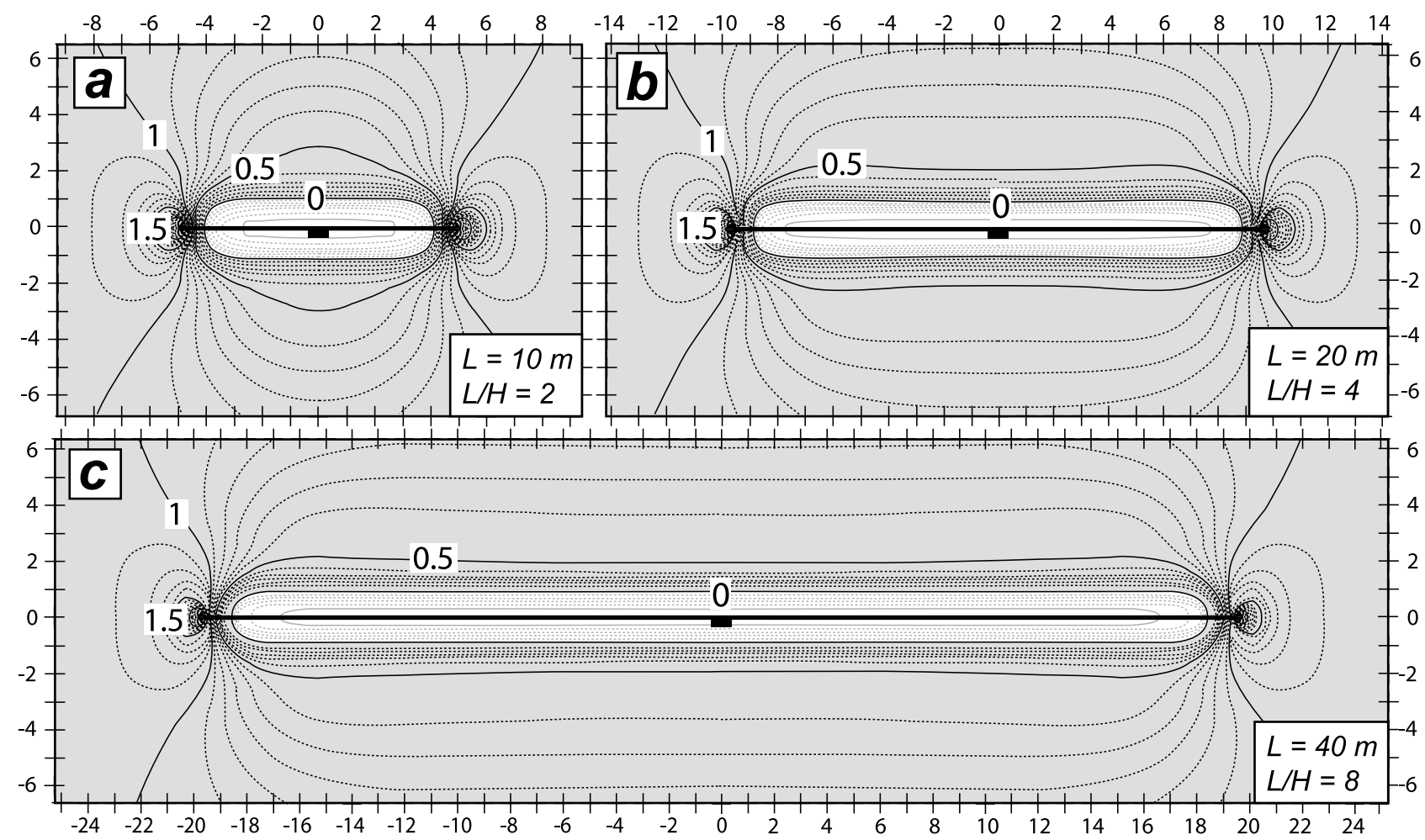

Figure 11. Map views of horizontal observation planes through the center of modeled faults of different length and aspect ratios (see the labeled values in Figures 11a, 11b, and 11c). Thin lines are contours of maximum coulomb shear stress normalized to the remote values (perturbed $S_{\mathrm{c}} /$ remote $S_{\mathrm{c}}$ ) with values labeled. The white zones with grey contours are areas of perturbed $S_{c} /$ remote $S_{\mathrm{c}}<0$. Numbers labeled at the boundary of the modeled horizons are horizontal scales in meters.

[30] These results indicate that the fault aspect ratio, and especially the short dimension of the faults strongly controls the horizontal extent of the quasi-static stress reduction around faults (Figures 11, 12a, 12b). The computed extent of quasi-static stress for faults that change in their aspect ratio is not proportional to the increase of the horizontal length, but is instead linearly related to the short fault dimension (Figures 12b and 12c). In confined fault systems, the short fault dimension is mainly governed by the presence of discontinuity levels at which vertical restriction occurs [e.g., Nicol et al., 1996; Schultz and Fossen, 2002]. Hence the position of the stress drop around the faults should be linearly related to the thickness of the brittle layer. This relation is predicted in Figure 12c, which reveals the small and limited dependence of the stress drop position to layer thickness ratio (range of 0.032 ) on variations in fault length.

\section{Interpretation and Discussion: Importance of Layer Thickness}

\subsection{Correspondence Between Fault Spacing and the} Ability of Faults to Link

[31] The correspondence between the limiting spacing ( $S \sim 1 \mathrm{~m}$, Figure $6 \mathrm{~b}$ ), the upper scalar limit for linkage (for $S \sim 1 \mathrm{~m}$, Figure 8 ) and the position of the highest stress drop gradient on the modeled faults (at $x \sim 1 \mathrm{~m}$, Figures 11 and 12), all suggest that the minimum spacing between faults of the same dip direction at Fumanyá was driven by the shear stress drop contours around the vertically restricted faults. We have shown that the position of the shear stress drop is in turn controlled by fault height, so that the layer thickness of the mechanical unit confining the faults should be of strong importance for the fault density and the scaling of fault linkage in the fault population from Fumanyá.

[32] Fault linkage is generally related to the position of the perturbed stress field at which collateral fault propagation is retarded [Aydin and Schultz, 1990; Willemse, 1997; Gupta and Scholz, 2000; d'Alessio and Martel, 2004]. This would explain why few overlapping fault tips are observed within the main computed surface area of stress drop reported on the overlap versus separation graph (see Figure 13). To maintain its propagation, a fault that continues to grow within the stress drop zone of an adjacent fault needs to produce more shear stress at its tip to reach the inherent strength of the rock mass, which occurs by the increase of the near tip displacement gradient [e.g., Gupta and Scholz, 2000]. This fault interaction leads to fault linkage at the relay ramp because of the fault tip reorientation or the formation of throughgoing faults (see Peacock and Sanderson [1991], Cartwright et al. [1996], and Soliva and Benedicto [2004] for field observations and Bürgmann et al. [1994], Crider and Pollard [1998], Kattenhorn et al. [2000], Ackermann et al. [2001], and Marchal et al. [2003] for numerical/analogue models). This process is illustrated by the overlap and separation data of the linked faults present in the zone of low values of $S_{\mathrm{c}}$ (Figure 13). 
[33] Concerning the case of nearly collinear faults (very small values of separation on Figure 13), linkage occurs with a small amount of overlap by the coalescence of the zones of stress increase near fault tips [Crider and Pollard,
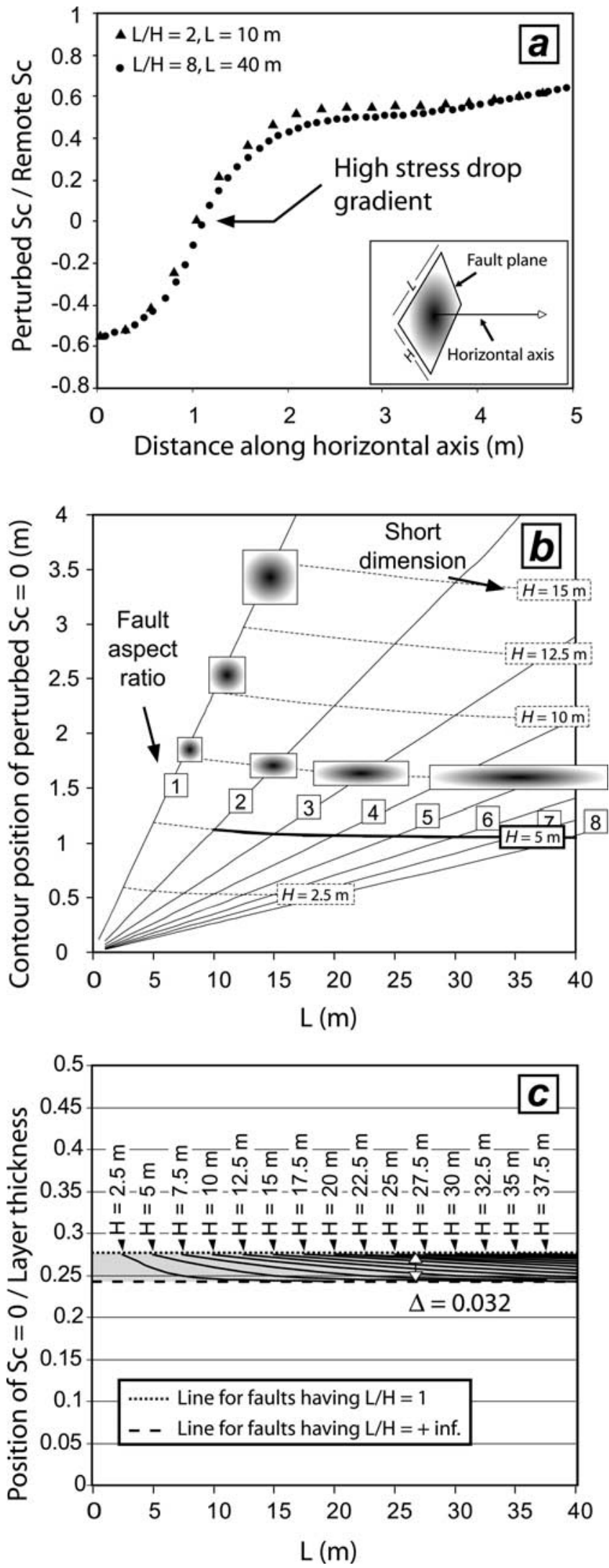

1998]. On the other hand, if the fault spacing exceeds $1 \mathrm{~m}$ at Fumanyá, which is about the location of the steep stress drop near the modeled faults of $H=5 \mathrm{~m}$ (Figures 11, 12b, and 13), then faults can propagate without linkage because of their low interaction [Gupta and Scholz, 2000; Schultz, 2000]. The tendency of the stress drop to locate around a distance of $1 \mathrm{~m}$ from the fault therefore provides a reasonable explanation for why linked faults have an upper bound of spacing $\sim 1 \mathrm{~m}$ (Figure 8 ). This allows us to relate the observed critical spacing $\left(S^{*}=1 \mathrm{~m}\right)$, defined as (1) the minimum value of fault spacing and (2) the maximum spacing for which parallel faults can link, to the short dimension $(H)$ of the vertically restricted faults, and therefore to the thickness of the carbonate sequence in which the faults are confined (Figure 14a).

[34] Since a single normal fault cannot increase indefinitely in length, because its ability to accumulate displacement and propagate horizontally degrades as its aspect ratio increases (see the decrease of fault end displacement gradient in Figure 4c and discussion by Soliva et al. [2005]), a single fault cannot accommodate the progressive increase of strain and many faults are required in the mechanical layer [Benedicto et al., 2003; Soliva and Benedicto, 2005]. The increase of length, density, and the reduced spacing between faults that would have nucleated randomly, should favor the stress shadowing process to increase within the mechanical unit [Cowie et al., 1995, Cladouhos and Marret, 1996; Cowie, 1998a]. In this scenario, linkage is allowed between the vertically restricted faults with spacing less than $1 \mathrm{~m}$, and the shadowing development progressively cluster the nonrestricted short faults that did not sufficiently interact with the long faults to be linked with them (Figure 14a). More precisely, a relay ramp formed between a short fault segment (small displacement) and a long segment could presumably not reach the linkage criterion expressed by Soliva and Benedicto [2004] as the ratio of displacement to fault spacing at relay zone. At Fumanyá, the fault propagation and infill with the occurrence of a critical spacing $S^{*}=$ $1 \mathrm{~m}$ should ultimately favor a nearly regular spacing distribution between the vertically restricted faults (as

Figure 12. (a) Profile of perturbed $S_{c}$ /remote $S_{\text {c }}$ (i.e., normalized Coulomb shear stress), measured along the horizontal line normal to fault strike from the fault center (see the illustration), for two modeled faults of different dimensions (fault aspect ratio equal to $L / H=2$ and $L / H=8$, see Figures 11a and 11c). (b) Graph of contour position of perturbed $S_{\mathrm{c}}=0$ versus $L$ of faults having variable aspect ratio and dimensions. The contour position of perturbed $S_{\mathrm{c}}=$ 0 is taken on a horizontal line as shown in Figure 12a. The thin black lines represent faults growing with constant aspect ratio with values labeled. The thin dashed lines represent faults growing only by length, i.e., with constant heights with values labeled. The thick black line represents a fault of height restricted at $H=5 \mathrm{~m}$, varying from an aspect ratio of 2 to an aspect ratio of 8. (c) Graph of position of perturbed $S_{\mathrm{c}}=0 /$ layer thickness versus $L$ of faults having variable aspect ratio and constant heights (labeled on graph). The layer thickness $\left(T=H \sin 60^{\circ}\right)$ is the thickness of the horizontal layer containing the fault. 


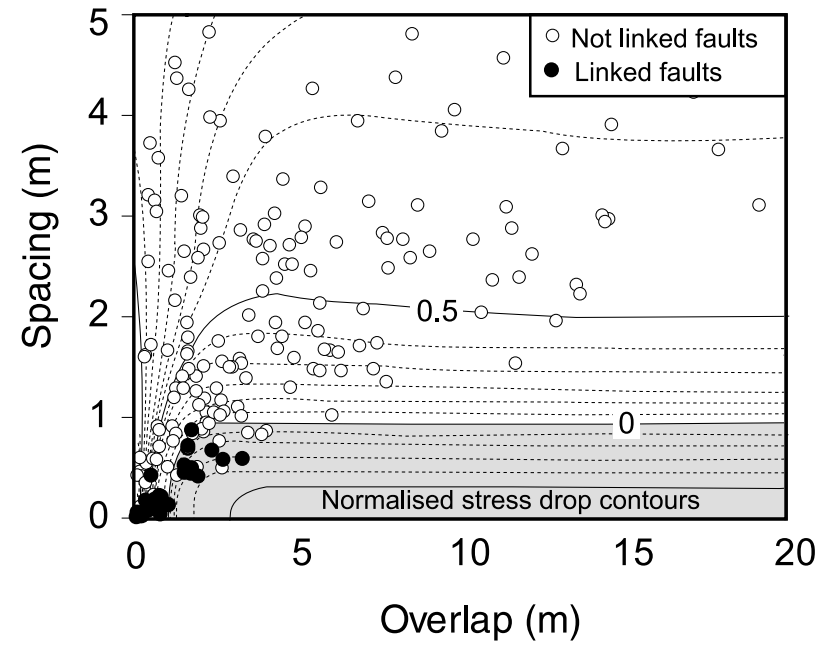

Figure 13. Overlap versus spacing graph including the data presented in Figure 8 superposed on the computed contours of $S_{c}$ of a fault of half length $=20 \mathrm{~m}$ and $H=5 \mathrm{~m}$. The grey area is the zone of $S_{c}<0$. White dots represent the position of fault tips for nonlinked faults on the overlap zone. Black dots represent the spacing and the amount of overlap for linked faults.

observed in the field, Figures 2a and 6b) (Figure 14b). Since the proportion of long faults is large in this fault population (Figure 7) (also see Ackermann et al. [2001] for mono clay layer models and Cowie et al. [1994] and Cowie [1998b] for mid-ocean ridges), the nearly regular fault spacing between long faults is a major geometrical characteristic of the fault population.

[35] As shown by Figure 6b, the spacing between faults is logarithmic-normal, which is also observed in joint sets reaching a certain degree of saturation (i.e., joint spacing stops evolving and remains constant [see Narr and Suppe, 1991; Wu and Pollard, 1995]). Although frictional slip conditions occurring on faults strongly differs from those in jointing processes, both the shape (very long and confined with flat topped aperture profile [Petit et al., 1994]), their parallel disposition, and the similarities of linkage at overlapping zones (hook shapes in joint sets and breached relay ramps in fault system) suggests that similar distribution can arise. This is probably because (1) the distribution of positive normal stress around mode I fractures resembles the mean zone of shear stress reduction around fault surfaces (e.g., Bai and Pollard [2000] and Bonafede and Rivalta [1999] for opening fractures and Willemse [1997] and Gupta and Scholz [2000] for faults) and (2) the stress concentration near fracture tips is one of the major characteristics of the fracturing process in general [Paris and Sih, 1965]. We must note that the spacing between short faults (not restricted) is not regular and is therefore different than the distribution of confined faults and joints. That regular spacing occurs between vertically restricted faults and joints is consistent, however, clustering of short faults [Cowie et al., 1995; Cladouhos and Marret, 1996; Cowie, 1998a] as well as spacing between conjugate faults [e.g., Golombec, 1979; Scholz and Contreras, 1998; Bahroudi et al., 2003] are inherent to the process of faulting and illustrate the strong difference between joint sets and fault populations.

\subsection{Importance of Material Properties}

[36] Variation in shear or Young's modulus of the material modifies the maximum slip [Cowie and Scholz, 1992; Bürgmann et al., 1994] and therefore has a large effect on the magnitude of the stress drop, but theoretically no effect on the extent of the perturbed stress field [Willemse, 1997]. Only variations in material compressibility (Poisson's ratio) within the range of allowable limits for sediments (0.03 to 0.35 [Hatheway and Kiersch, 1989]) are effective on the position of stress gradient variations, but is secondary compared to the effect of fault shape, especially to the fault aspect ratio [Willemse, 1997]. Bourne and Willemse [2001] also show how fault aspect ratio is the main influence on the shape of the stress perturbation around the fault rather than the elastic constants. The contrasts of material properties within the lithological alternation, not considered in this

\section{a. Fault infill}

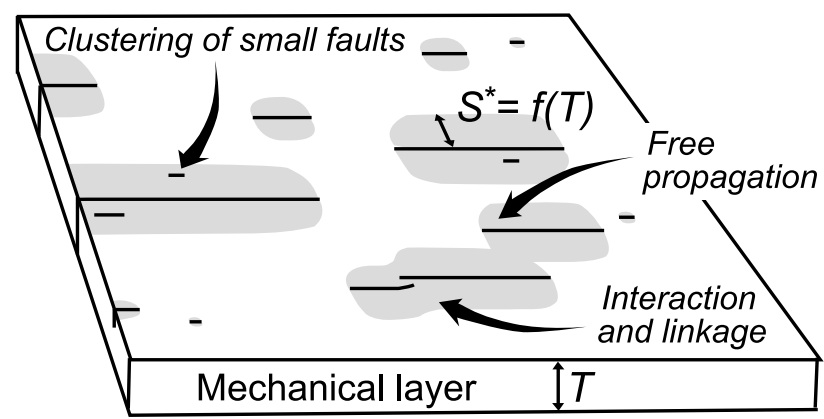

\section{b. Saturation}

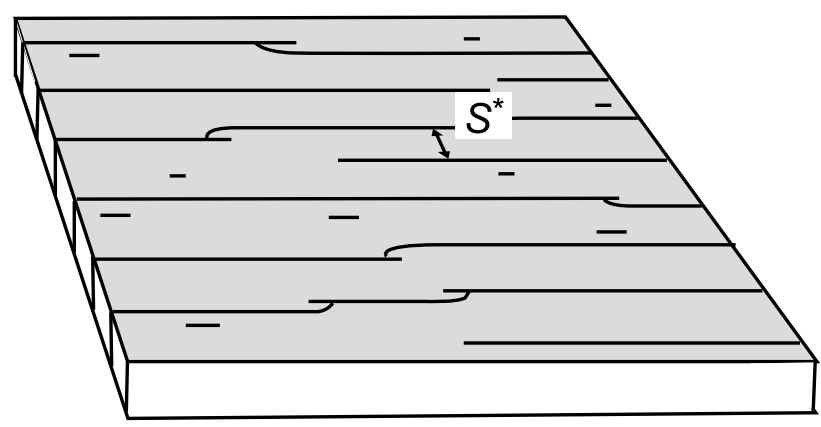

\section{Nearly regular spacing between large faults}

Figure 14. Conceptual sketch showing the development of normal faults having the same dip direction within a mechanical layer. (a) First stage of the development of faults. Fault initiation occurs following a hypothetical random distribution of the strength heterogeneity. Fault density increase in the volume of the mechanical layer occurs by initiation, lateral propagation and linkage. Grey areas represent the stress shadow, which controls the critical spacing $\left(\mathrm{S}^{*}\right)$ and allows the clustering of short faults, i.e., the minimum value of fault spacing and the maximum spacing for fault linkage at relay ramps. (b) Final stage of fault development showing a more regular spacing distribution. 


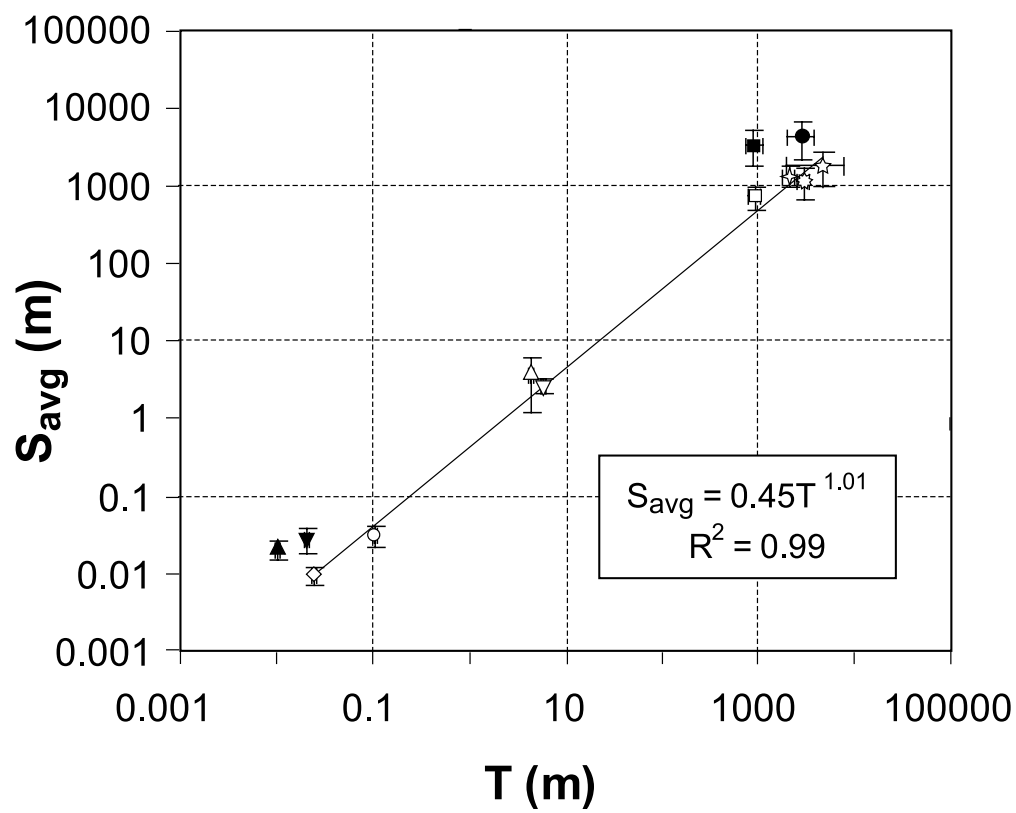

Non-listric faults

- McClay, 1996

$\diamond \quad$ Bahroudi et al., 2003

$\triangle$ Present study

$\nabla$ Arches National Park, US, (unpublished)

$\square \quad$ Stewart and d'Argent, $2000-1$

Evamy et al., 1978

$\&$ Bailey et al., 2003

\& Searle et al., 1998

\section{Listric faults}

- Stewart and d'Argent, $2000-2$

- Séranne et al., 1995

\ Mauduit et al., 1997 - 1

V Mauduit et al., 1997 - 2

Figure 15. Bilogarithmic graph of average spacing $\left(S_{\mathrm{avg}}\right)$ versus layer thickness $(T)$ including both the studied data set and other published data sets over a large-scale range. Listric fault shapes above ductile material and nonlistric planar faults over nonconservative barriers are distinguished by different symbols (see text for explanation). Line on graph is the best fit linear trend of nonlistric faults with equation and least squares coefficient labeled.

paper, should also affect the extent of the shear stress perturbation and then probably fault spacing [e.g., Cook, 1971; Bonafede and Rivalta, 1999]. For example, Bürgmann et al. [1994] show that strong contrasts of material properties (ratios of Young's modulus from 0.1 to 10) can account for an amount of maximum displacement modified by a factor 2 . This relative effect compared to the wide variation in Young's modulus suggests that the main controlling parameter is the thickness of the mechanical unit in which the faults are confined, and that contrasts of material properties could allow a component of scatter in spacing/layer thickness ratios. Bai and Pollard [2000], with two-dimensional mode I fracture models, show that fracture spacing strongly depends on the thickness of the layer, and that contrasts in material properties between the fractured layer and the neighboring layers encompasses the often cited spacing to layer thickness ratio. In three-dimensional modeling (i.e., for various aspect ratio), the absence of contrasts in material properties and cohesive end zones could account for the small discrepancy observed between the field data trend and the modeled displacements of Figure 10, which should asymptote with a slight obliquity.

\subsection{Fault Spacing/Thickness Ratio Over a Broad Range of Scales}

[37] Layer thickness, which controls fault down dip height, seems the major parameter controlling the spacing between faults having the same dip direction. Because the extent of the shear stress reduction is predicted to scale linearly with the short dimension of faults (Figure 12b), we expect a linear relation between spacing of faults having the same dip direction and the thickness of the layer confining the faults (Figure 12c), as occurs for mode I fracture sets
[Narr and Suppe, 1991; Wu and Pollard, 1995; Bai and Pollard, 2000].

[38] Figure 15 shows the data of thickness $(T)$ and average spacing $\left(S_{\mathrm{avg}}\right)$ between faults of same dip direction from fault systems containing a significant number of faults confined to a discrete mechanical layer. These parameters have been measured on cross-sectional views or map views of analogue models and natural examples from field, seismic survey, and sonar bathymetry images [Evamy et al., 1978; Séranne et al., 1995; McClay, 1996; Mauduit et al.,1997; Searle et al., 1998; Stewart and d'Argent, 2000; Bahroudi et al., 2003; Bailey et al., 2003]. Error bars for $T$ represent thickness variations of the units confining the faults, and/or possible range of conversion from time to depth on seismic data. Error bars for $S_{\text {avg }}$ are plus and minus spacing standard deviation. Listric and nonlistric fault shapes [e.g., McClay, 1996] are distinguished because of their characteristic difference in $S_{\text {avg }} / T$ ratio. Nonlistric faults show $0.337<S_{\mathrm{avg}} / T<0.782$, whereas listric faults have $1.33<S_{\mathrm{avg}} / T<3.39$, revealing that a single curve should not be use to describe all the data. The change of dip inherent to a listric shape provides roughly different geometrical conditions than planar faults with steep angle against a horizontal barrier (nonconservative barrier [King and Yielding, 1984]). The progressive change of dip toward a flat detachment level implies larger fault height and displacement (compare displacement created by listric and confined domino faults, for example, of McClay [1996]), probably producing a larger extent of the stress reduction.

[39] Regardless the specific case of listric faulting, a nearly linear trend (see the exponent $n=1.01$, close to 1 ) seems quite relevant for the collected data. As suggested above, scatter of $T / S_{\text {avg }}$ ratio should be related to the 
contrasts of material properties between the mechanical unit and the barrier. The results from this tendency (Figure 15) and numerical modeling (Figure 12) suggest that fault spacing can be linearly dependent to layer thickness in the sediment cover and probably also at crustal scale. Heterogeneous rheological layering in the upper crust can therefore control the spatial distribution of faults over a broad range of scales.

\section{Conclusion}

[40] A nearly regular fault spacing of a normal fault population confined to a discrete mechanical layer commonly occurs in nature and is frequently reproduced in analogue modeling (so-called "domino-style" or "bookshelf" faults [Mandl, 1987; Vendeville et al., 1987; McClay, 1990; Ackermann et al., 2001; Bahroudi et al., 2003]). Such behavior occurs at different scales, depending on the thickness of the layering [e.g., Séranne et al., 1995; Mauduit et al., 1997; Cowie, 1998b; Bailey et al., 2003]. On the basis of field observations, we have analyzed the statistics of a fault population confined to a carbonate layer and their consistency with the computed shear stress distributions around faults of variable aspect ratios. We observe a nearly regular spacing of long faults with a minimum spacing value $(\sim 1 \mathrm{~m})$ that corresponds to the maximum separation between linked parallel long faults at relay ramps. In this fault population, field observations and numerical modeling reveal that the position of the maximum stress drop should tend toward a constant distance of $1 \mathrm{~m}$ to the fault when faults of equal height increase in length. Assuming that within the zone of low values of shear stress, fault propagation and the activity of small fault are inhibited whereas relay ramp formation is favored, we infer that the short dimensions of the vertically restricted faults (i.e., the height), and then the thickness of the mechanical layer leads to the observed nearly regular fault spacing. Comparison of the spacing/thickness ratio with other fault sets suggests the thickness of a mechanical unit confining the faults can control the extent of the stress reduction and therefore fault spacing at different scales. This constitutes a physical explanation for why some fault population show distributed strain in layered media.

[41] Our results suggest that for the case of a fault population growing confined to a discrete mechanical layer [e.g., Ackermann et al., 2001; Schultz and Fossen, 2002], the thickness of the layer controls the upper limit of spacing for which two confined faults can link together. Although fault transfer zones can be described as self similar in shape [Aydin and Nur, 1982; Peacock, 2003] and that the scaling of fault linkage at relay ramps is described as linear on a broad range of scale [Soliva and Benedicto, 2004], we provide here an example of limited scaling of fault ability to strongly interact and link. Considerable efforts have been made in the identification of the geometrical parameters revealing the degree of fault interaction at relay zones [Aydin and Nur, 1982; Aydin and Schultz, 1990; Gupta and Scholz, 2000; Schultz, 2000; Accocella et al., 2000; Cowie and Roberts, 2001; Soliva and Benedicto, 2004]. This paper reveals the limitation of any criterion of fault interaction or linkage that only considers 2-D earth surface geometric parameters of fault arrays (such as the length of fault segments, fault overlap and fault separation) that do not take into account the thickness of the mechanical layer, or parameter function of the short dimension such as fault displacement. The strong control of the down dip fault dimension is therefore of major importance in the evaluation of mechanical interaction and propagation of active fault segments.

[42] Acknowledgments. We acknowledge David Pollard from Stanford University and Frantz Maerten from IGEOSS for use of the software Poly3DGUI. We thank David Peacock and an anonymous reviewer for their positive and constructive review and also the Associate Editor Isabelle Manighetti for the critiques that led to substantial modification of an earlier version of the paper. Patience Cowie made a helpful review which improved and sharpened the final version of the paper. Discussions and advices from Richard Schultz, Atilla Aydin, and Thierry Rives were appreciated. We thank Carbones de Berga S.A. and especially Joan Llobet, who granted us access to the Figols quarry and climbing on the outcrops. This work was carried out in the context of a Ministère de l'Education Nationale de la Recherche et de la Technologie thesis fellowship.

\section{References}

Accocella, V., A. Gudmundsson, and R. Funiciello (2000), Interaction and linkage of extension fractures and normal faults: Examples from rift zone of Iceland, J. Struct. Geol., 22, 1233-1246.

Ackermann, R. V., and R. W. Schlische (1997), Anticlustering of small normal faults around larger faults, Geology, 25, 1127-1130.

Ackermann, R. V., R. W. Schlische, and M. O. Withjack (2001), The geometric and statistical evolution of normal fault systems: An experimental study of the effects of mechanical layer thickness on scaling laws, J. Struct. Geol., 23, 1803-1819.

Aydin, A., and A. Nur (1982), Evolution of pull-apart basin and their scale independence, Tectonics, 1, 91-105.

Aydin, A., and R. A. Schultz (1990), Effect of mechanical interaction on the development of strike-slip fault with en echelon patterns, J. Struct. Geol., $12,123-129$.

Bahroudi, A., H. A. Koyi, and C. J. Talbolt (2003), Effect of ductile and frictional décollements on style of extension, J. Struct. Geol., 25, $1401-$ 1423

Bai, T., and D. D. Pollard (2000), Fracture spacing in layered rocks: A new explanation based on the stress transition, J. Struct. Geol., 22, 43-57.

Bailey, W., P. M. Shannon, J. J. Walsh, and V. Unnithan (2003), The spatial distribution of faults and deep sea carbonate mounds in the Porcupine Basin, offshore Ireland, Mar. Pet. Geol., 20, 509-522.

Barnett, J. A. M., J. Mortimer, J. H. Rippon, J. J. Walsh, and J. Watterson (1987), Displacement geometry in the volume containing a single normal fault, $A A P G$ Bull., 71, 925-937.

Benedicto, A., R. A. Schultz, and R. Soliva (2003), Layer thickness and the shape of faults, Geophys. Res. Lett., 30(20), 2076, doi:10.1029/ 2003GL018237.

Bonafede, M., and E. Rivalta (1999), The tensile dislocation problem in a layered elastic medium, Geophys. J. Int., 136, 341-356.

Bourne, S. J., and E. J. M. Willemse (2001), Elastic stress control on the pattern of tensile fracturing around a small fault network at Nash Point, UK, J. Struct. Geol., 23, 1753-1770.

Bürgmann, R., D. D. Pollard, and S. J. Martel (1994), Slip distributions on faults: Effects of stress gradients, inelastic deformation, heterogeneous host-rock stiffness, and fault interaction, J. Struct. Geol., 16, 1675-1690.

Cartwright, J. A., B. Trudgill, and C. S. Mansfield (1995), Fault growth by segment linkage: An explanation for scatter in maximum displacement and trace length data from the Canyonlands Grabens of SE Utah, J. Struct. Geol., 17, 1319-1326.

Cartwright, J. A., C. Mansfield, and B. Trudgill (1996), The growth of normal fault by segment linkage, in Modern Developments in Structural Interpretation, Validation and Modeling, edited by P. G. Buchanan and D. A. Nieuwland, Geol. Soc. Spec. Publ., 99, 163-177.

Childs, C., J. Watterson, and J. J. Walsh (1995), Fault overlap zones within developing normal fault systems, J. Geol. Soc. London, 152, 535-549.

Cladouhos, T. T., and R. Marret (1996), Are fault growth and linkage models consistent with power-law distributions of fault lengths?, J. Struct. Geol., 18, 281-293.

Cook, T. S. (1971), Flaws in wedges, Ph.D. thesis, Lehigh Univ., Bethlehem, $\mathrm{Pa}$.

Cooke, M. L., and C. A. Underwood (2001), Fracture termination and step-over at bedding interfaces due to frictional slip and interface opening, J. Struct. Geol., 23, 223-238. 
Cowie, P. A. (1998a), A healing-reloading feedback control on the growth rate of seismogenic faults, J. Struct. Geol., 20, 1075-1087.

Cowie, P. A. (1998b), Normal fault growth in three dimensions in continental and oceanic crust, in Faulting and Magmatism at Midocean Ridges, Geophys. Monogr. Ser, vol. 106, edited by R. Buck et al., pp. 325-348, AGU, Washington, D. C.

Cowie, P. A., and G. P. Roberts (2001), Constraining slip rates and spacing for active normal faults, J. Struct. Geol., 23, 1901-1915.

Cowie, P. A., and C. H. Scholz (1992), Physical explanation for the displacement-length relationship of fault using a post-yield fracture mechanics model, J. Struct. Geol., 14, 1133-1148.

Cowie, P. A., and Z. K. Shipton (1998), Fault tip displacement gradients and process zone dimensions, J. Struct. Geol., 20, 983-997.

Cowie, P. A., A. Malinverno, W. B. F. Ryan, and M. H. Edwards (1994), Quantitative fault studies on the East Pacific Rise: A comparison of sonar imaging techniques, J. Geophys. Res., 99, 15,205-15,218.

Cowie, P. A., D. Sornette, and C. Vanneste (1995), Multifractal scaling properties of a growing fault population, Geophys. J. Int., 122, 457-469.

Crider, J. G., and D. D. Pollard (1998), Fault linkage: Three-dimensional mechanical interaction between echelon normal fault, J. Geophys. Res., $103,24,373-24,391$

d'Alessio, M. A., and S. J. Martel (2004), Fault terminations and barriers to fault growth, J. Struct. Geol., 26, 1885-1896.

Dawers, N. H., M. H. Anders, and C. H. Scholz (1993), Growth of normal faults: Displacement-length scaling, J. Struct. Geol., 21, 1107-1110.

dePolo, C. M. (1998), A reconnaissance technique for estimating the slip rates of normal-slip faults in the Great Basin, and application to faults in Nevada, USA, Ph.D. thesis, 223 pp., Univ. of Nev., Reno.

Evamy, B. D., J. Haremboure, P. Kamerling, W. A. Knaap, F. A. Molloy, and P. H. Rowlands (1978), Hydrocarbon habitat of the Tertiary Niger Delta, AAPG Bull., 62, 1-39.

Fossen, H., and J. Hesthammer (1997), Geometric analysis and scaling relations of deformation bands in porous sandstone, J. Struct. Geol., 19, 1479-1493.

Golombec, M. P. (1979), Structural analysis of lunar grabens and the shallow crustal structure of the Moon, J. Geophys. Res., 84, 4657-4666.

Gross, M. R. (1993), The origin and spacing of cross joints: Examples from Monterey Formation, Santa Barbara coastline, California, J. Struct. Geol., $15,737-751$.

Gross, M. R., G. Gutiérrez-Alonso, T. Bai, M. A. Wacker, K. B Collinsworth, and R. J. Behl (1997), Influence of mechanical stratigraphy and kinematics on fault scaling relations, J. Struct. Geol., 19, 171-183.

Guglielmo, J. G., B. C. Vendeville, and M. P. A. Jackson (2000), 3-D visualization and isochore analysis of extensional diapers overprinted by compression, AAPG Bull., 84, 1095-1108.

Gupta, A., and C. H. Scholz (2000), A model of normal fault interaction based on observation and theory, J. Struct. Geol., 22, 865-879.

Hatheway, A. W., and G. A. Kiersch (1989), Engineering properties of rock, in Practical Handbook of Physical Properties of Rocks and Minerals, edited by R. S. Carmichael, pp. 672-715, CRC Press, Boca Raton, Fla.

Huggins, P., J. Watterson, J. J. Walsh, and C. Childs (1995), Relay zone geometry and displacement transfer between normal faults recorded in coal-mine plans, J. Struct. Geol., 17, 1741-1755.

Jaeger, J. C., and N. G. W. Cook (1979), Fundamentals of Rock Mechanics, 585 pp., CRC Press, Boca Raton, Fla.

Kattenhorn, S. A., and D. D. Pollard (2001), Integrating 3D seismic data, field analogs and mechanical models in the analysis of segmented norma faults in the Wytch Farm oil field, southern England, AAPG Bull., 85, $1183-1210$

Kattenhorn, S. A., A. Aydin, and D. D. Pollard (2000), Joints at high angles to normal fault strike: An explanation using 3D numerical model of faultperturbated stress field, J. Struct. Geol., 22, 1-23.

King, G. C. P., and G. Yielding (1984), The evolution of a thrust fault system: Processes of rupture initiation, propagation and termination in the 1980 El Asnam (Algeria) earthquake, Geophys. J. R. Astron. Soc., 77, 915-933.

Koledoye, A. B., A. Aydin, and E. May (2000), Three dimensional visualization of normal fault segmentation and its implication for fault growth, Leading Edge, 19, 691-701.

Larsen, P. H. (1988), Relay structures in a Lower Permian basementinvolved extension system, East Greenland, J. Struct. Geol., 10, 3-8.

Leveille, G. P., R. Knipe, C. More, D. Ellis, G. Dudley, G. Jones, Q. J. Fisher, and G. Allinson (1997), Compartmentalization of rotliegendes gas reservoirs by sealing faults, Jupiter field area, southern North Sea, in Petroleum Geology of the Southern North Sea: Future Potential, edited by K. Ziegler, P. Turner, and S. R. E. Daines, Geol. Soc. Spec. Publ., 123, $87-104$.

Maerten, L., E. J. M. Willemse, D. D. Pollard, and K. Rawnsley (1999), Slip distribution on intersecting normal faults, J. Struct. Geol., 21, $259-271$.
Mandl, G. (1987), Tectonic deformation by rotating parallel faults: The "bookshelf" mechanism, Tectonophysics, 141, 277-316.

Manihgetti, I., G. King, Y. Gaudemer, C. Scholz, and C. Doubre (2001), Slip accumulation and lateral propagation of active normal fault in Afar, J. Geophys. Res., 106, 13,667-13,696.

Mansfield, C. S., and J. A. Cartwright (1996), High resolution fault displacement mapping from three-dimensional seismic data: Evidence for dip linkage during fault growth, J. Struct. Geol., 18, 249-263.

Mansfield, C., and J. Cartwright (2001), Fault growth by linkage: Observations and implications from analogue models, J. Struct. Geol., 23, 745763.

Marchal, D., M. Guiraud, and T. Rives (2003), Geometric and morphologic evolution of normal fault planes and traces from 2D to 4D data, J. Struct. Geol., 25, 135-158.

Martel, S. J., and W. A. Boger (1998), Geometry and mechanics of secondary fracturing around small three-dimensional faults in granitic rocks, J. Geophys. Res., 103, 21,299-21,314.

Mauduit, T., G. Guerin, J.-P. Brun, and H. Lecanu (1997), Raft tectonics, the effects of basal slope angle and sedimentation rate on progressive extension, J. Struct. Geol., 19, 1219-1230.

McClay, K. R. (1990), Extensional fault systems in sedimentary basins: A review of analogue models studies, Mar. Pet. Geol., 7, 206-233.

McClay, K. R. (1996), Recent advances in analogue modeling: Uses in section interpretation and validation, in Modern Developments in Structural Interpretation, Validation and Modeling, edited by P. G. Buchanan and D. A. Nieuwland, Geol. Soc. Spec. Publ., 99, 163-177.

Muraoka, H., and H. Kamata (1983), Displacement distribution along minor fault traces, J. Struct. Geol., 5, 483-495.

Narr, W., and J. Suppe (1991), Joint spacing in sedimentary rocks, J. Struct. Geol., 13, 1037-1048.

Nicol, A., J. Watterson, J. J. Walsh, and C. Childs (1996), The shapes, major axis orientations and displacement patterns of fault surfaces, J. Struct. Geol., 18, 235-248.

Olson, J. E. (2003), Sublinear scaling of fracture aperture versus length: An exception or the rule?, J. Geophys. Res., 108(B9), 2413, doi:10.1029/ 2001JB000419.

Paris, P. C., and G. C. Sih (1965), Stress analysis of cracks, in Fracture Toughness Testing and Its Application, pp. 30-81, Am. Soc. for Test. of Mater., Philadelphia, Pa.

Peacock, D. C. P. (2003), Scaling of transfer zones in British Isles, J. Struct. Geol., 25, 1561-1567.

Peacock, D. C. P., and D. J. Sanderson (1991), Displacement, segment linkage and relay ramps in normal fault zones, J. Struct. Geol., 13, $721-733$

Petit, J.-P., G. Massonat, F. Pueo, and K. Rawnsley (1994), Mode 1 fracture shape ratio in layered rocks: A case study in the Lodève Permian Basin (France), Bull. Cent. Rech. Explor. Prod. Elf Aquitaine, 18, 211-229.

Rives, T., M. Razack, J.-P. Petit, and K. Rawnsley (1992), Joint spacing: Analogue and numerical simulations, J. Struct. Geol., 14, 925-937.

Scholz, C. H. (1982), Scaling laws for large earthquakes: Consequences for physical models, Bull. Seismol. Soc. Am., 72, 1-14.

Scholz, C. H., and J. C. Contreras (1998), Mechanics of continental rift architecture, Geology, 26, 967-970.

Scholz, C. H., and A. Gupta (2000), Fault interaction and seismic hazard, J. Geodyn., 29, 459-467.

Schultz, R. A. (2000), Fault-population statistics at the valles Marineris Extensional Province, Mars: Implication for segment linkage, crustal strain, and its geodynamical development, Tectonophysics, 316, 169193

Schultz, R. A., and H. Fossen (2002), Displacement-length scaling in three dimensions: The importance of aspect ratio and application to deformation bands, J. Struct. Geol., 24, 1389-1411.

Searle, R. C., P. A. Cowie, N. C. Mitchell, S. Allerton, C. J. MacLeod, J. Escartin, S. M. Russel, P. A. Slootweg, and T. Tanaka (1998), Fault structure and detailed evolution of a slow spreading ridge segment: The Mid-Atlantic Ridge at $29^{\circ} \mathrm{N}$, Earth Planet. Sci. Lett., 154, 167-183.

Séranne, M., A. Benedicto, P. Labaume, C. Truffert, and G. Pascal (1995), Structural style and evolution of the Gulf of Lion Oligo-Miocene rifting: Role of the Pyrenean orogeny, Mar. Pet. Geol., 12, 809-820.

Soliva, R., and A. Benedicto (2004), A linkage criterion for segmented normal faults, J. Struct. Geol., 26, 2251-2267.

Soliva, R., and A. Benedicto (2005), Geometry, scaling relation and spacing of vertically restricted normal faults, J. Struct. Geol., 27, 317-325.

Soliva, R., R. A. Schultz, and A. Benedicto (2005), Three-dimensional displacement-length scaling and maximum dimension of normal faults in layered rocks, Geophys. Res. Lett., 32, L16302, doi:10.1029/ 2005 GL023007.

Spyropoulos, C., W. J. Griffith, C. H. Scholz, and B. E. Shaw (1999), Experimental evidence for different strain regimes of crack populations in a clay model, Geophys. Res. Lett., 26, 1081-1084. 
Stewart, S. A., and J. d'Argent (2000), Relationship between polarity of extensional fault arrays and presence of detachments, J. Struct. Geol., 22, $693-712$.

Thomas, A. L. (1993), Poly3D: A three-dimensional, polygonal element, displacement discontinuity boundary element computer program with applications to fractures, faults, and cavities in the earth's crust, M. S. thesis, Stanford Univ., Stanford, Calif.

Trudgill, B., and J. Cartwright (1994), Relay ramp forms and normal-fault linkages, Canyonlands National Park, Utah, Geol. Soc. Am. Bull., 106, $1143-1157$.

Vendeville, B., P. R. Cobbold, P. Davy, J. P. Brun, and P. Choukroune (1987), Physical models of extensional tectonics at various scales, in Continental Extensional Tectonics, edited by M. P. Coward, J. F. Dewey, and P. L. Hancock, Geol. Soc. Spec. Publ., 28, 95-107.

Vergés, J., and A. Martinez-Rius (1988), Corte compensado del Pireneo oriental: Geometria de las cuencas de ante-paisy edades de empezamiento de los mantos de corrimiento, Acta Geol. Hisp., 23, 95-106.

Vergés, J., and J. A. Muňoz (1990), Thrust sequences in the southern central Pyrenees, Bull. Soc. Geol. Fr, 8, 265-271.

Walsh, J. J., and J. Watterson (1989), Displacement gradients on fault surfaces, J. Struct. Geol., 11, 307-316.

Walsh, J. J., W. R. Bailey, C. Childs, A. Nicol, and C. G. Bonson (2003), Formation of segmented normal faults: A 3-D perspective, J. Struct. Geol., 26, 399-400.
Wilkins, S. J., and M. R. Gross (2002), Normal fault growth in layered rocks at split mountain, Utah: Influence of mechanical stratigraphy on dip linkage, fault restriction and fault scaling, J. Struct. Geol., 24, 14131429.

Willemse, E. J. M. (1997), Segmented normal faults: Correspondence between three-dimensional mechanical models and field data, J. Geophys. Res., 102, 675-692.

Willemse, E. J. M., D. D. Pollard, and A. Aydin (1996), Three-dimensional analyses of slip distributions on normal fault arrays with consequences for fault scaling, J. Struct. Geol., 18, 295-309.

Wu, H., and D. D. Pollard (1995), An experimental study of the relationship between joint spacing and layer thickness, J. Struct. Geol., 17, 887-905.

A. Benedicto, Department de Sciences de la Terre, UMR 7072, F-91405 Orsay cedex, France. (antonio.benedicto@geol.u-psud.fr)

L. Maerten, IGEOSS, Cap Omega, Rond Point Benjamin Franklin CS3951, F-34960 Montpellier Cedex 2, France. (laurent.maerten@igeoss. com)

R. Soliva, Department de Sciences de la Terre et de l'Environnement, UMR 5573, Place Eugene Bataillon, F-34095 Montpellier cedex 5, France. (solivaroger@yahoo.fr) 